\title{
LA CERTIFICACIÓN DE ARMAS DE LA FAMILIA FERNÁNDEZ DE JÁUREGUI EN MÉXICO. UN ANÁLISIS DOCUMENTAL Y LIGATORIO
}

\author{
THE CERTIFICATION OF ARMS OF THE FERNÁNDEZ DE JÁUREGUI \\ FAMILY IN MEXICO. A DOCUMENTARY ANALYSIS OF ITS \\ BOOKBINDING
}

\author{
Yohana Yessica Flores Hernández \\ Universidad Complutense de Madrid \\ amoxtlan@gmail.com
}

\section{José María De Francisco Olmos \\ Universidad Complutense de Madrid}

\section{Resumen}

Este estudio analiza el manuscrito "Carta ejecutoria de la familia Fernández de Jáuregui”, que se conserva en la Biblioteca Nacional de México (ms. 10158). Es una revisión detallada de carácter documental y tipológico, que trata igualmente temas heráldicos y genealógicos, lo que al mismo tiempo resalta y justifica la encuadernación como elemento de distinción en documentos de carácter administrativo. También se realiza un detallado análisis histórico acerca de qué es una carta ejecutoria, una certificación de armas, y quién era la familia Fernández de Jáuregui, además de describirse la encuadernación desde diversos apartados como los materiales utilizados, las técnicas de construcción, la decoración y el estado de conservación. Todo ello nos aporta una visión de conjunto y nos hace establecer unas conclusiones sobre la procedencia, el periodo y el tipo de encuadernación, y con ello clarificar el motivo de la familia Fernández de Jáuregui para encargar este documento.

Palabras clave: certificación de armas, heráldica, genealogía, encuadernación, México.

\begin{abstract}
This paper analyzes a manuscript known as "Carta ejecutoria de la familia Fernández de Jáuregui”, preserved today at the National Library of Mexico. A thorough documentary and a typological review (including its genealogical and heraldic aspects) permits us to stress the importance of binding as an element of distinction formerly used in administrative documents. An explanation on the differences between a carta ejecutoria and a certificación de armas and the history of the Fernández de Jauregui family is also offered. By describing its materials, manufacturing technique, ornamentation and state of preservation, we attempt to establish the possible origin and dating of this type of binding, as well to clarify the reasons of its commissioning by the Fernández de Jáuregui family.
\end{abstract}

Keywords: certification of arms, heraldry, genealogy, bookbinding, Mexico.

\section{Información del artículo}

Recibido: 10 de noviembre de 2018.

Aceptado: 28 de mayo de 2019.

DOI: 10.22201/iih.24486922e.2019.61.67689 


\section{INTRODUCCIÓN}

El trabajo que presentamos a continuación analiza el manuscrito titulado "Carta ejecutoria de la familia Fernández de Jáuregui", uno de los manuscritos más peculiares de la Biblioteca Nacional de México (ms. 10158), ya que refleja claramente los usos administrativos y jurídicos propios de la cultura española, pero que también se implementó en la sociedad novohispana y, al igual que éste, muchos otros documentos de distinta índole son al mismo tiempo, una muestra de la tradición ligatoria que se heredó y aprendió en el México del virreinato. ${ }^{1}$

El análisis que aquí se presenta comprende dos puntos de vista: uno que se encarga del contenido documental y otro del aspecto material. El primero ayudará a conocer la verdadera tipología documental de este texto, que nos aporta una importante información sobre la genealogía de la familia Fernández de Jáuregui, y el segundo, analizará la encuadernación que el documento tiene, describiendo las técnicas y los materiales que la constituyen, para poder así, exponer cómo las características de la encuadernación también responden a la naturaleza del documento.

\section{OBjetivos, METODOLOGía Y JUSTIFICACIÓN}

Dado el tipo de estudio, la técnica que se empleó fue analítico-descriptiva, siguiendo un método basado en la observación y cotejo de los elementos a describir. Por otra parte los objetivos que planteamos tienen que ver con la función del documento y los dividimos en el objetivo general y en objetivos específicos; el objetivo general se refiere a la definición del carácter tipológico y ligatorio del documento; y los objetivos específicos tienen que ver con el desarrollo del documento en sí, por qué y para qué se hizo, así como su validez jurídica, y también determinar el tipo de encuadernación.

La realización de este estudio ayudará a comprender parte de la tradición administrativa que se implementó en México después del estableci-

${ }^{1}$ El término ligatorio-a es una locución latina que se emplea para referirse al arte de la encuadernación. Proviene del verbo ligare, que significa atar, sujetar, y dado que en un sentido fáctico, la encuadernación es la unión de cuadernos, ambos vocablos ligatorio y encuadernación se emplean indistintamente. Cabe mencionar que, por ejemplo, en italiano, que es el idioma más cercano al latín, la palabra encuadernación se traduce directamente por legatura. 
miento de los españoles, además de resaltar el papel de la encuadernación en este tipo de documentos.

\section{EL MANUSCRITO \\ "CARTA EJECUTORIA DE LA FAMILIA FERNÁNDEZ DE JÁUREgui"}

Este es el nombre que recibe el documento a estudiar en su actual catalogación, que nosotros creemos que no es el acertado. Para eso debemos analizar en primer lugar qué es una carta ejecutoria y ver si se ajusta a las características de este manuscrito.

La carta ejecutoria es un documento emitido por un tribunal que obliga a las partes al cumplimiento de una sentencia, y en nuestro caso el mayor número de estas cartas está ligado al reconocimiento a un individuo de su condición de hidalgo, es decir a su nobleza de sangre, lo que conllevaba una serie de privilegios anejos, en especial de tipo económico y social. En España estas ejecutorias las emitían las chancillerías y junto al documento puramente jurídico, el demandante podía solicitar que se hiciera una copia de dicha carta ricamente iluminada, como luego veremos, que en muchas ocasiones incluía el escudo de armas de la persona a la que se había reconocido su condición de hidalgo, que de hecho era la marca exterior de dicha condición, además de ratificar la antigüedad del linaje y la descendencia por legitimidad de nacimiento, así como la limpieza de sangre de sus miembros. Por todo ello solía ser bien encuadernada, ya que se convertía en una pieza clave del archivo familiar que podía usarse siempre y cuando se pusiera en entredicho por cualquier institución esa condición de hidalgo, o bien como prueba adicional para solicitar otras mercedes; por ello, se puede decir que: "La 'carta ejecutoria de hidalguía' era un documento de gran importancia para el linaje que lo obtenía ya que, de ahí en adelante, no se tenía más que probar su pertenencia al mismo por línea de varón para acreditar su hidalguía”. ${ }^{2}$ En este contexto, y en lo que a su aspecto estético respecta:

Los testimonios escritos llamados "cartas ejecutorias de hidalguía" resultan muy atractivos ya que constituyen una valiosa fuente de información para investigadores de diversas especialidades. Archiveros, diplomatistas, paleógrafos, genealogistas,

${ }^{2}$ Huidobro (2015). Véanse sobre este tema los recientes trabajos de Ladrón de Guevara e Isasa (2016); y del mismo autor en colaboración con Moreno Almárcegui (2016). 
heraldistas, historiadores del arte, juristas, modernistas, sociólogos y, asimismo, estudiosos de otras disciplinas. ${ }^{3}$

Estas ejecutorias se solicitaban cuando en un momento concreto las autoridades exigían el pago de determinados impuestos a un individuo, y éste se negaba a ello alegando su condición de hidalgo. ${ }^{4}$ Es en ese momento cuando las partes recurrían a los tribunales para dirimir quién tenía razón, aportando cada parte las pruebas que considerase necesario. Por tanto, la carta ejecutoria de hidalguía es en realidad la plasmación material de una sentencia judicial que se entrega a una de las partes, obviamente siempre que fuera favorable al demandante de reconocimiento de la hidalguía. Estos pleitos fueron muy frecuentes, y tan abundantes que las Ordenanzas de los Reyes Católicos de 1489 especificaban que uno de los cuatro tribunales superiores de la Chancillería de Valladolid fuera precisamente la llamada Sala de los Hijosdalgo, que estaba presidida por un alcalde mayor. Es a partir de este momento cuando los pleitos de hidalguía se conforman tal y como hoy los conocemos, y se mantienen sin cambios hasta el final del Antiguo Régimen en las dos chancillerías de la Corona de Castilla (Valladolid y Granada), que centralizaron todos los procesos relacionados con este tema.

En el proceso se hacían diversas averiguaciones centradas en buscar testimonios sobre la antigüedad del linaje del demandante, así como la legitimidad del nacimiento de sus ascendientes por línea de varón y su limpieza de sangre, que se probaba, más que por documentos, que la verdad son escasos en los primeros tiempos, por testigos de avanzada edad que daban fe de que el linaje investigado era considerado noble desde hacía mucho tiempo (hidalgo notorio), y para que estas declaraciones fueran claras se creó un formulario específico para redactarlas, donde se buscaban datos sobre el interesado y sus ascendientes, sus casamientos, su legitimidad (no ser bastardo ni espurio, ni descender de moros, judíos o conversos),

${ }^{3}$ Ruiz García (2006), que seguimos aquí para explicar el contenido y la estructura de estos documentos.

${ }^{4}$ Por ello se fueron conformando poco a poco en la mayoría de los municipios los llamados "padrones de hidalguía", donde se recogía a todas las personas exentas del pago de impuestos por su condición de hidalgo. Los ayuntamientos solían ser muy restrictivos en este tema, y por ello, se negaban a reconocer esta condición hidalga a muchos de sus vecinos, y en especial a los que se trasladaban desde otros lugares, por lo cual era muy frecuente que el litigio entre ambas partes terminara en el tribunal de la Chancillería, que debía emitir sentencia sobre el tema y la correspondiente carta ejecutoria. 
no haber sido preso ni penitenciado por el Santo Oficio, que no pechó (pagó impuestos) en las anteriores derramas reales o concejiles (siendo el motivo de ello ser considerado de condición noble), haber tenido ciertos cargos (reservados a los nobles), pertenecer a cofradías o formar parte de los alardes propios de los caballeros, etcétera. Estas declaraciones eran la prueba fundamental para que el tribunal dictara sentencia.

Esta sentencia, más o menos extensa en función de las pruebas aportadas, era originalmente un documento administrativo hecho en papel y escrito en una letra cursiva procesal, que obviamente tenía toda la fuerza legal que necesitaba el demandante. Pero el contenido era tan importante para el hidalgo reconocido como tal y para sus descendientes, que normalmente solicitaba al tribunal que se hiciera un original más solemne para ser guardado en los archivos familiares, siendo éste realizado en pergamino y con una caligrafía muy cuidada y en forma de cuaderno, siendo validado por el sello de plomo del monarca. ${ }^{5}$ La iluminación de este documento "de aparato" dependía de las posibilidades económicas del agraciado; podemos encontrar desde las iniciales ornamentadas, hasta grandes ilustraciones relacionadas con temas religiosos a plana completa (Crucifixión, la Inmaculada, la Anunciación, Santiago apóstol, algunos santos específicos, etcétera) o bien retratos del rey que concede la hidalguía o del agraciado, sólo o acompañado de su familia, y sobre todo un gran escudo con las armas familiares, que es la muestra específica de la condición hidalga del beneficiario, ${ }^{6}$ todo lo cual nada añade a la fuerza jurídica del documento. ${ }^{7} \mathrm{Y}$ para conservar este importante documento a lo largo del tiempo normalmente se ordena encuadernarla de

5 Tras la resolución del pleito, el litigante disponía de un plazo de sesenta días para encargar esta versión especial de la sentencia.

${ }^{6}$ Ahora bien, estos diseños heráldicos no tienen nada que ver con la sentencia de la Chancillería, ni en la mayoría de los casos están "oficializados" por un rey de armas; son dibujos realizados a instancia de parte, por lo cual llaman la atención algunos de los elementos que aparecen en ellos, bastante extraños, que muestran el intento de colocar en los mismos elementos de "leyendas" familiares que buscan asegurar el ennoblecimiento del linaje con alguna empresa heroica en la que participaron sus antepasados, sin más respaldo que el deseo y las "órdenes" del recipiendario de la sentencia al dibujante que había contratado.

${ }^{7}$ Que adquiría toda su fuerza una vez que recibía el sello real de plomo y era registrado, siendo luego entregado al beneficiario tras pagar las oportunas tasas. El hidalgo reconocido notificaba luego al Concejo donde residía el resultado del litigio y pedía su cumplimiento, a lo cual accedía el concejo mediante un acta notarial que se incorporaba al documento original y concluía con ello el proceso. 
una manera especial, más o menos lujosa, como vemos en las que han llegado hasta nosotros. ${ }^{8}$

Resumiendo, la carta ejecutoria de hidalguía es un documento expedido por los tribunales de la Sala de los Hijosdalgo de las chancillerías de Valladolid o de Granada, a petición de parte, y cuyo contenido esencial es la sentencia dictada por los correspondientes jueces, en virtud de la cual se amparan los derechos de los reclamantes sobre su condición de hidalgo. Dicho todo lo anterior, hay que decir que el documento que estamos estudiando no es una carta ejecutoria de hidalguía, a pesar de estar catalogado como tal.

Por tanto, ¿̇de qué documento se trata? Las características que presenta obedecen más bien a lo que se denomina una certificación de armas. Ya hemos dicho que en la mayor parte de las ejecutorias de hidalguía se añade el escudo de armas propio del beneficiario de la misma, que era de hecho el signo externo más claro de su condición, y normalmente este escudo era pintado según los deseos del recipiendario de la ejecutoria, sin más avales "científicos" ni "documentales", pero a partir del siglo XVII 9 se busca tener un documento específico que avale la "legalidad" del blasón familiar, y esa es la certificación de armas. Este documento lo emitía un oficial real concreto, el llamado rey de armas, cuyo origen se remonta a la época medieval y que poco a poco fue adquiriendo mayores responsabilidades. Ya en época de los Austrias los encontramos realizando numerosas certificaciones de armas, además de una forma muy reglamentada, y así se mantuvieron durante siglos. En España tenemos ejemplos de su labor hasta bien entrado el siglo xx. Como ejemplo de ello podemos citar las palabras del rey de armas Joseph Alfonso de Guerra y Villegas, que dice: "A cargo de los reyes de armas, araldos, farautes o parsavantes está el declarar, emendar o determinar las dudas que cada día se ofrecen sobre la forma que se debe esculpir, pintar, o bordar, los escudos de las armas reales y de quantos, según su dignidad, estado, y nobleza puedan usar armas". ${ }^{10}$

Estos documentos se inician con la intitulación del rey de armas, luego se añade el nombre del peticionario y a continuación el oficial detalla (con

${ }^{8}$ Matilla (2000).

${ }^{9}$ Aunque ya se conocen algunos ejemplos desde al menos el siglo xv, éstos son muy escasos.

${ }^{10}$ Guerra y Villegas (1693, f. 4), en ella el autor se titula "Chronista General" de S. M., "su Rey de armas más antiguo en todos sus Reynos, y Chronista Mayor de los Prioratos de la Sacra Orden de San Juan, de Castilla, y León, y de las Militares y Cavallería de Santiago, Calatrava y Alcántara”. 
más o menos extensión) el origen de los linajes paterno y materno, su antigüedad, hechos importantes y sobre todo describe las armas de cada uno de ellos, que al final conforman el escudo certificado, que normalmente aparece al inicio del cuadernillo. Del mismo modo explica el significado de los colores y figuras que lo componen y por último el rey de armas firma y sella el documento garantizando la veracidad del mismo según los documentos y libros que constan en los archivos de su oficio. Para dar fuerza legal al documento se ratificaba por un escribano público, que daba fe y garantía del proceso seguido por el rey de armas, añadiendo su signo y sello de oficio, lo cual se hacía en presencia de testigos que firmaban el documento, asegurando la validez total del proceso. Y todo esto es lo que tenemos en el documento tradicionalmente denominado "Carta ejecutoria de la familia Fernández de Jáuregui”, que debería pasar a catalogarse como "Certificación de armas de Joseph Fernández de Jáuregui" y que ahora vamos a comentar con cierto detalle ${ }^{11}$ para explicar la formación de la misma y el motivo de su realización.

\section{EL CONTENIDO DE LA CERTIFICACIÓN}

Se inicia con un diseño a toda página de un escudo de armas cuartelado, que muestra las armas de los linajes Fernández de Jáuregui, Ojirando, Urrutia y Arana, y a continuación, también a plana completa, una ilustración con el escudo real, propio del papel sellado de la época de Fernando VI, con las grandes armas de la monarquía usadas por los primeros Borbones rodeadas por los collares de las órdenes del Toisón de Oro y de la francesa del Espíritu Santo, y debajo el nombre del rey de armas que va a certificar el documento,

${ }^{11}$ Cabe mencionar también que, por extensión, se utiliza también el término ejecutoria para las certificaciones de apellidos, testamentos y otros documentos, que en su forma externa buscaron parecerse a las ejecutorias de lujo, pero consideramos mejor y sobre todo más correcto el nombre que le hemos dado. Recordando que una carta ejecutoria era una sentencia con verdadera fuerza jurídica validada con el sello de plomo custodiado en la Chancillería, mientras la certificación de armas no tenía esa categoría en ningún caso, a pesar de que los reyes de armas tuvieran personalidad jurídica, incluso sello propio, y sus estudios fueran avalados por otros funcionarios con su firma y sello, en realidad este documento no era más que un estudio más o menos histórico y avalado por noticias de otros manuscritos, cronísticas o de tradición, según constaba en el propio archivo del rey de armas, sobre la historia, antigüedad, hazañas y armas de un linaje. La mayor parte de las veces era una invención que conformaba un relato bien novelado. 
don Juan Alphonso Guerra y Sandoval ${ }^{12}$ (figura 1), añadiendo sus títulos en la siguiente página, ${ }^{13}$ y certificando que en los libros y papeles originales que se encuentran en el "Archivo del Real Cargo de nuestros Empleos" están los apellidos de Fernández de Jáuregui, Ojirando, Urrutia y Arana, su origen, armas y significados, añadiendo después que son los correspondientes a don Joseph Fernández de Jáuregui, a quien se dirige este blasón. ${ }^{14}$

A continuación describe la historia y las armas de dichos linajes, ${ }^{15}$ y termina dando fe de la infanzonía e hidalguía de sangre de dichas casas y por tanto de su descendiente, el peticionario, que es:

Christiano viejo limpio de toda mala raza de moros, judíos, mulatos, nuevamente convertidos o castigados por el Santo Oficio de la Inquisición; ni otra alguna secta

${ }^{12}$ Este rey de armas era hijo de José Alfonso de Guerra y Villegas, que ocupó en propiedad la segunda plaza de rey de armas (de las cuatro que había) desde 1688 hasta 1722, siendo uno de los más grandes tratadistas que ha tenido este oficio; fue caballero de Santiago (1712) y teniente de aposentador mayor de la reina (1688); y de María de Sandoval Barros y Molina. Sucedió a su padre en 1722 en la segunda plaza de rey de armas, la cual ocupó hasta su muerte en Madrid el 28 de octubre de 1753 (aunque ya era de armas supernumerario desde 1707). Fue caballero de Santiago (1695), cronista de su majestad (sucediendo en el oficio al eminente don Luis de Salazar y Castro), regidor decano de Toledo y su procurador en Cortes, etcétera. Más datos sobre su figura y obra en Ceballos-Escalera y Gila (1993); y Guillén Berrendero (2009) y Andrés (1990, pp. 373-402).

13 "Cavallero del orden de Santiago, Chronista maior y rey de Armas Principal, y más antiguo del Rey Nuestro Señor Don Fernando Sexto (que Dios guarde) en todos sus Dominios y Señoríos; y Mayor de la Sacra Orden y Religión de San Juan en los de Castilla y León, y de las Militares de Santiago, Calatrava y Alcántara”.

${ }^{14}$ Cuya personalidad y genealogía comentaremos más adelante.

${ }^{15}$ Las armas de los Fernández de Jáuregui (f. 15v) "se organizan de un escudo partido en pal, la parte primera en aspa arriba en campo rojo castillo de oro, avajo en plata águila negra desplegadas las alas; y en los dos lados en azul cinco estrellas de oro. La parte segunda partida en faja en primero en campo de oro una encina verde con bellotas de oro, y un jabalí negro andante al pie. Y en segundo en azul lisonja de oro y dentro castillo formal azul, puertas y ventanas rojas, y en cada hueco una estrella de oro de ocho rayos. Como van iluminadas en el primer quartel del Escudo que da principio a esta Certificación, en cuya forma, y no en otra corresponden a dicho Don Joseph Fernández de Jáuregui”. Ogirando (f. 20): "Un escudo en campo de plata con dos lobos negros andantes, lenguas y vergas rojas, puestos en faja; orla roja con ocho autores de oro". Urrutia (f. 23v): "Un escudo en campo rojo, y en él una cruz de oro hueca y floreteada con cinco panelas de plata una en cada ángulo, y la otra en medio de la cruz". Arana (f. $27 \mathrm{r} \mathrm{y} \mathrm{v):} \mathrm{"Un} \mathrm{escudo} \mathrm{partido} \mathrm{en} \mathrm{faja,} \mathrm{la} \mathrm{parte} \mathrm{de} \mathrm{arriba} \mathrm{de} \mathrm{oro}$ con un pino verde con sus piñas de oro y empinantes a él dos lobos pardos uno a cada lado, las raíces descubiertas; y en la parte de avajo tres fajas azules ondeadas en campo de plata, y orla de oro con ocho aspas rojas". 
infesta; y Noble Hidalgo de Sangre de Casa Solar Infanzonado y conocido, de los de devengar quinientos sueldos áureos, según Fuero de España. ${ }^{16}$

Termina diciendo que el peticionario podrá usar el Escudo de Armas que inicia la Certificación de la forma que se expresa y no en otra, ${ }^{17} \mathrm{y}$ por ello, a su pedimento da fe, y firma y sella el documento en Madrid a diez de octubre de 1752 (figura 2).

A continuación varios escribanos públicos de la "Imperial y Coronada Villa de Madrid" certifican la validez ("entera fe y crédito en juicio y fuera del") de los escritos de Juan Alfonso Guerra y Sandoval como rey de armas, y como tal lo firman el mismo día antes dicho. Por último Vicente Francisco Verdugo, secretario mayor, perpetuo y más antiguo del Ayuntamiento de Madrid, certifica todo lo anterior, lo firma y lo sella con "las Armas de Madrid" (figura 3). ${ }^{18}$

\section{EL SOLICITANTE}

En la certificación de armas se cita repetidas veces que se hace a pedimento de don Joseph Fernández de Jáuregui, y a lo largo del texto se habla de sus padres y abuelos, unas veces citándolos de forma expresa con nombre, apellido y lugar de origen y otras de forma genérica. A continuación haremos una breve semblanza del personaje y sus relaciones familiares con México (véase árbol genealógico).

La relación de sus familiares con México se inicia con Juan de Urrutia, nacido en Llanteno (Álava) el 1 de diciembre de 1645. A los 20 años marchó a México y allí hizo fortuna, siendo mercader de plata, capitán

${ }^{16}$ F. 28v. Y a continuación pasa a explicar el significado de sus armas, ya que "siendo estas un geroglífico o emblema que en breve demostración da a entender tanto, y porque hay muchos Cavalleros que ignoran las gloriosas representaciones de los metales, colores y figuras de que se organizan sus Armas" (ff. 29v-34).

${ }^{17}$ F. 35 r y v. "[C]olocándolas en sus Sellos, Anillos, Reposteros, Casas, Capillas, Portadas, Sepulturas, Pinturas, Plata Labrada y demás parages y Alhajas, que les convenga en público y en secreto sin que por ello se les ponga embarazo, ni impedimento alguno por ningún Tribunal Eclesiástico ni Seglar; entrar con ellas en desafíos de campaña, justas, sortijas, torneos, fiestas reales y otros actos de honor concedidos y permitidos a los Cavalleros Nobles Hijosdalgo de España".

${ }^{18}$ Como ejemplo de un estudio integral de este tipo de documentos podemos citar el de Piqueras García (2005, pp. 83-111). 


\section{ÁRBOL GENEALÓGICO}

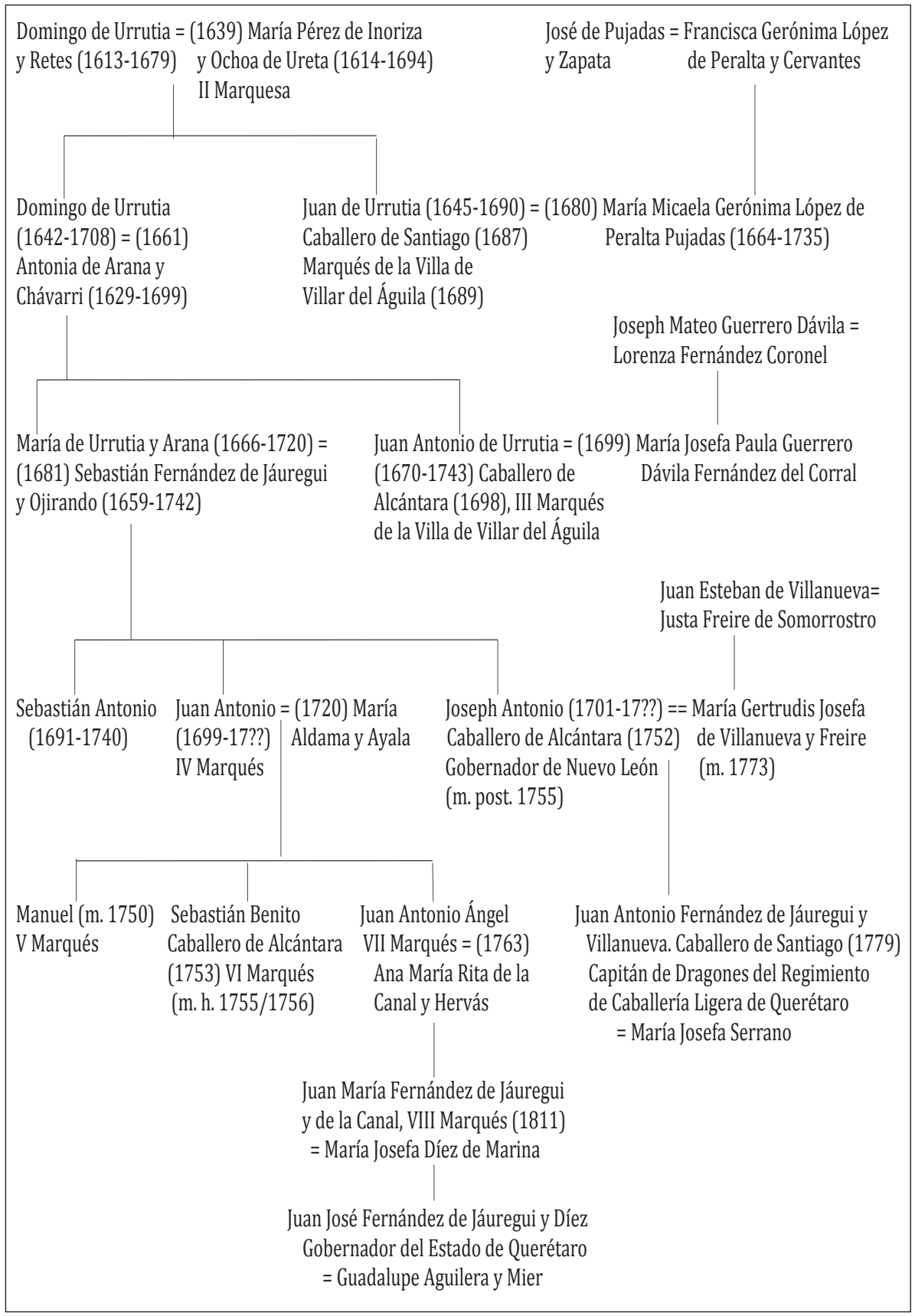


de Caballos Corazas, alguacil mayor del Tribunal del Santo Oficio de la Inquisición de la Nueva España, caballero de la Orden de Santiago (1687), ${ }^{19}$ alcalde provisional ordinario de la Ciudad de México, etcétera, y allí se casó con una importante heredera, María Micaela Gerónima López de Peralta Pujadas y Zapata, ${ }^{20}$ pasando entonces a ser conocido

${ }^{19}$ Archivo Histórico Nacional, España (en adelante, AHN), Órdenes Militares. CaballerosSantiago, exp. 8367. Sobre estas mercedes de hábitos a caballeros residentes en Nueva España, véanse Martínez Cosío (1946); y Lohmann Villena (1947).

${ }^{20}$ Sobre la historia del mayorazgo López de Peralta son imprescindibles las obras de Rosas García (2012 y 2015); y la obra de Pérez Rocha (2018), que ahora resumo. Jerónimo López "El Mozo" (hijo de Gerónimo López "el Viejo”, uno de los participantes en la Conquista de México, que en 1528 compró en España ganado diverso y lo introdujo en la Nueva España, y tuvo en encomienda el pueblo de Axacuba desde 1538, y de Catalina Álvarez de la Cerda, natural de Badajoz), encomendero de Axacuba, regidor de la ciudad de México, tesorero de la Real Hacienda, etcétera, casó en segundas nupcias con Ana Carrillo de Peralta (hija de Pedro de Yanguas y de Ana Carrillo de Peralta, sobrina del que fue virrey de la Nueva España en 1566-1567, don Gastón de Peralta, marqués de Falces), y establecieron tres mayorazgos (19 de mayo de 1608) para sus descendientes: el primero para su hijo mayor superviviente, Gabriel López de Peralta (con un valor de 294000 pesos de oro común y una renta anual de 24920 pesos); el segundo para el siguiente hijo varón, Francisco (con un valor de 235000 pesos de oro común y con una renta anual de 14900 pesos); y el tercero fue para su nieto, Jerónimo (con un valor de 136000 pesos de oro común y con una renta anual de 11950 pesos), hijo del mayor de sus hijos varones (Gerónimo, muerto en 1607, y de su esposa, Clara de Rivadaneira). A nosotros nos interesa el segundo mayorazgo, que era una de las cláusulas que "el sucesor o sucesora de este mayorazgo, después de muertos los dichos Jerónimo López y Ana Carrillo de Peralta, llevaran el sobrenombre de Jerónimo o Jerónima, y utilizaran los apellidos López de Peralta, para que de esta forma fueran reconocidos". Francisco López de Peralta fue alcalde ordinario de la ciudad de México, alcalde de la mesta, etcétera, y casó con Francisca Núñez de Solís Morquecho (hija del oidor de la Real Audiencia de la ciudad de México, el licenciado Diego Núñez de Morquecho, caballero de Santiago). De ese matrimonio nació su única hija, Jerónima de San Crisóstomo López de Peralta, quien casó con Andrés Cervantes de Carvajal, regidor de la ciudad de México y alcalde de la Santa Hermandad (hijo de Francisco Cervantes y de Ana Cano de Molina, y nieto de María Carvajal, hija del conquistador Antonio de Carvajal). Hija y heredera de este matrimonio fue Francisca Jerónima López de Peralta, quien en 1661 casó con el capitán José de Pujadas y Zapata (aragonés de Calatayud, alcalde mayor de las provincias de Colima y de Oaxaca, sobrino del beato Juan de Palafox y Mendoza, obispo de Puebla de los Ángeles y virrey en 1642). Su hija y sucesora en el mayorazgo fue María Micaela Gerónima López de Peralta Pujadas y Zapata (1664-1735), que el 15 de octubre de 1680 casó con Juan de Urrutia y Retes. Quedó viuda el 8 de agosto de 1690, y luego se unió en matrimonio con Tomás Terán de los Ríos, caballero de Santiago, presidente de la Real Audiencia de Guadalajara, etcétera, y murió sin dejar descendencia. Pasó entonces este mayorazgo a su sobrina, Francisca Javiera López de Peralta Luyando y Bermeo, hija de su hermana, Josefa Antonia de Pujadas y Cervantes, que había casado con Luis Miguel de Luyando y Bermeo. 
como Juan Gerónimo López de Peralta y Urrutia, por exigirlo así las normas sucesorias del mayorazgo de su esposa. ${ }^{21}$ En 1689 obtiene título de Castilla con la denominación de Marqués de la Villa de Villar del Águila, ${ }^{22}$ y muere en 1693, sin descendencia, en México. ${ }^{23}$

${ }^{21}$ Más datos en "Testamento de don Juan Jerónimo López de Peralta y Urrutia, Caballero de Santiago y marqués del Villar del Águila” (México, 1704), Archivo General de la Nación (en adelante, AGN), Bienes Nacionales, 1704, vol. 861, exp. 2, f. 1r; Artís Espriu (1994, p. 30); y Zárate Toscano (2005, p. 477). Esta variación del nombre era obligatoria, el padre de María Micaela también cambió su nombre de José de Pujadas y Zapata al de José Gerónimo López de Peralta Pujadas y Zapata, como puede verse en numerosos documentos, más datos en Fernández de Recas (1965, p. 85).

${ }^{22}$ Marqués de Villa del Villar del Águila. Se concedió este título a D. Juan de Urrutia. 1687, Julio, 11. Nueva España, Archivo General de Indias (en adelante, AGI), Títulos de Castilla, 11, R. 5, f. 6r-6v. Mención de haberse creado el título de Marqués del Villar del Águila el 6 de junio de 1689, Ahn, Consejos, 5240, Rel.3Bis). Mención de don Juan de Urrutia, marqués de Villar del Águila, entre los títulos declarados vitalicios por Carlos II (1695), AHN, Consejos, 9270, Rel. 1. Recordemos que el aumento en este reinado de las concesiones nobiliarias por las dificultades económicas de la monarquía conllevó que se tomaran algunas medidas excepcionales para corregir estos excesos, así por real cédula de 13 de octubre de 1692 se ordenó que "todos los títulos que desde el primero de enero del año de 1680 acá se hubieren beneficiado en los dominios de Indias, en menos cantidad de la de 30000 pesos escudos de a 10 reales de plata, no pasen de los poseedores que hoy los tienen, sino que los gocen por su vida, y que los que quisiesen mantenerlos perpetuos en sus casas hayan de pagar la cantidad que faltare al cumplimiento de los 30000 pesos escudos" (AGN, Reales Cédulas Originales, v. 24, cédula 132, pp. 518-521. Es decir la mayor parte de los títulos otorgados en Nueva España por Carlos II dejaban de ser hereditarios y transmisibles para convertirse en un privilegio personal vitalicio si no cumplían las condiciones económicas antes comentadas, lo cual obligó a muchos de los concesionarios a hacer un importante desembolso para conseguir que su merced fuera de nuevo considerada hereditaria. Más datos sobre los motivos y las especificidades de estas concesiones nobiliarias en la introducción de la más reciente y documentada de las obras sobre este tema. Conde y Díaz-Rubín y Sanchiz Ruiz (2008).

${ }^{23}$ Sobre los títulos nobiliarios en Indias, es muy interesante la obra de Gómez de Olea y Bustinza (2005, pp. 30-33), en la cual detalla todas las concesiones a las familias novohispanas, que él cifra en noventa y ocho. La importancia de estas concesiones se ve en su escasez, en especial en época de los Austrias: así podemos citar un único título en el siglo XVI, el Marquesado del Valle de Oaxaca (1529); con Felipe III se conceden tres, el Marquesado de Salinas del Río Pisuerga (1609), el Condado de Santiago de Calimaya (1616) y el Marquesado de Villamayor de las Ibernias (1617); con Felipe IV, cinco: el Vizcondado de Ilucan y el Condado de Moctezuma de Tultengo (1627), el Condado del Valle de Orizaba (1627), el Vizconde de San Miguel (1627), Conde de Marcel de Peñalva (1649); y ya con Carlos II, bastantes más, diez y siete: son el Marquesado de San Miguel de Aguayo (1682), el Condado de Laguna de Términos (1689), el Condado de Miraflores (1689), el Marquesado de Villar del Águila (1689), el Condado de Loja (1690), el Marquesado del Valle de la Colina (1690), el Condado de Moraleda (1690), el Marquesado de Altamira de Puebla (1690), el Condado de Miravalle (1690), el Marquesado de Santa Fe de Guardiola (1690), el 
A su muerte dejó todos sus bienes y títulos a su anciana madre, quien lo sucedió en la lejana España, ${ }^{24}$ aunque de hecho su sucesor designado fue su sobrino Juan Antonio, hijo de su hermano Domingo. Este Juan Antonio de Urrutia y Arana ${ }^{25}$ nació en Llanteno en 1670, y se trasladó a

Condado de Santa Rosa (1691), el Marquesado de San Jorge (1691), el Condado del Fresno de la Fuente (1692), el Condado de Saucedilla (1693), el Marquesado de Montserrate (1695), el Marquesado de (San José) de Buenavista (1696) y el Marquesado de la Nava de Bárcinas (1699). A estas dignidades, Conde y Sanchiz (2005, pp. 11-12) opinan que deben añadirse las concesiones de adelantado mayor, ya fueran hereditarias (el de Yucatán, el mayor perpetuo de la Florida, el mayor perpetuo de las islas Filipinas, el mayor de Nueva Galicia) o a título personal (el de Nueva España a Hernán Cortés, el de Guatemala a Pedro de Alvarado, el de Nueva Vizcaya a Diego de Ibarra y Sáenz de Marquiegui, el de Zacatecas a Cristóbal Pérez de Oñate, el de Nuevo México a Juan de Oñate, o ya a inicios del siglo xviII el de Petén-Itzá a Martín de Ursúa y Arzimendi), recordándonos su inclusión que dentro del grupo de los títulos le da el arancel publicado en 1664 bajo el título Media-annata de las Mercedes. Reglas generales para su administracion, beneficio, y cobranza, formuladas en virtud e órdenes, y resoluciones de su Magestad, y expressadas en una su Real Cédula de tres de Julio de 1664, Madrid, por Joseph Fernández de Buendía, 1664, donde se recuerda una resolución de 14 de junio de 1634 que decía: "lo honorífico del Título de Adelantado en las Indias, está estimada la media-Annata de él en mil ducados, regulándose por mas que el de Vizconde, cuya estimación es 750 ducados" (p. 19), añadiendo luego en la entradilla específica de los Títulos de estos Reynos de España y Indias (número 47) que la Media-Anata de un título de conde o marqués serían 1500 ducados (según una resolución de 15 de octubre de 1631). Son obras de referencia también en este campo los clásicos trabajos de Ortega y Pérez Gallardo (1902, pp. 30-31) (Marquesado de Villar del Águila), y sobre todo (1908-1910), donde en el volumen I detalla la historia del Marquesado de Villar del Águila (pp. 202-217), copiando la carta de concesión del título ( 6 de julio de 1689) y añadiendo un escudo de armas de don Juan Urrutia y Arana, tomado de la oración fúnebre del marqués redactada por el R. P. fray Antonio Castrillón (1744), que dedica a su viuda, obra que se puede encontrar en el trabajo de Frías Camacho (1994), donde además del texto citado están también otras honras y oraciones fúnebres que le dedicaron años después el presbítero Braulio M. Guerra (1886) y Roberto Ugalde (1938).

${ }^{24}$ La anciana señora hizo testamento en 1694 y cita expresamente que es la heredera de los bienes y títulos de su hijo premuerto, mientras su nieto Juan Antonio actuaba en México como administrador de sus bienes. A la muerte de doña María Pérez de Inoriza, la heredó su hijo mayor, Domingo, que se tituló como tal Marqués de Villar del Águila hasta su muerte en 1708, pero cumpliendo los deseos de su hermano Juan traspasó todos los derechos de herencia a su hijo Juan Antonio, tomando éste posesión de la misma por cesión de su padre, siendo de hecho y de derecho el verdadero III Marqués (Certificado de carta de pago de media annata en 16 de junio de 1741 por don Juan Antonio de Urrutia Arana, tocante a la sucesión de doña María Pérez de Inoriza, su abuela, en el título de Marquesa de Villar del Águila, por muerte de su hijo el marqués don Juan de Urrutia; y a la del mencionado don Juan Antonio de Urrutia Arana, por muerte de la citada doña María su abuela, AHN, Consejos, 51586, exp. 1).

${ }^{25}$ Sobre este personaje existen varias monografías, la de Samaniego (1946); la de Loarca Castillo (1993); pero sobre todo la de Ramírez Montes e Iturrate (1979), de donde tomamos la mayor parte de los datos biográficos. 
México en 1687, siendo un fiel auxiliar de su tío, que lo llamó para convertirlo en su heredero; de hecho, poco después le traspasó el cargo de guarda mayor de la Casa de la Moneda (1690), durante el motín de 1692, producido por la escasez de maíz, participó en el restablecimiento del orden como capitán de Caballos Corazas, luego fue nombrado alcaide de la Alameda; entre 1694 y 1697 fue regidor de la ciudad, en 1696 obrero mayor y diputado de Propios, y hasta 1713 fue corregidor o justicia mayor de la Ciudad de México, cargo que abandonó para dedicarse a la gestión de sus numerosas propiedades. El 9 de febrero de 1699 se casó con una importante dama del país, doña María Josefa Paula Guerrero Dávila Fernández del Corral (m. 1754), ${ }^{26}$ con quien no tuvo descendencia. Fue marqués de Villar del Águila ${ }^{27}$ y caballero de la Orden de Alcántara (1698), ${ }^{28}$ trasladándose años

${ }^{26}$ Esta señora era heredera de varios importantes mayorazgos, como el de su abuelo materno, el capitán Francisco Fernández del Corral, pero sobre todo del que recayó en ella a la muerte de su padre, el conocido como mayorazgo Guerrero (en realidad había tres mayorazgos de esta familia, los dos primeros fundados por Juan Guerrero de Luna y su mujer Beatriz Gómez Dávila, hija de Rodrigo Gómez Dávila: el primero creado el 28 de diciembre de 1573 conocido luego como "el Grande"; el segundo fundado el 24 de junio de 1589 llamado Guerrero-Luna-Dávila, y el tercero de 26 de junio de 1666 creado por Melchor Guerrero Dávila, cuarto hijo de los fundadores, conocido como "el Chico", que tras la muerte de María Josefa se fusionaría con el Grande). Nuestra protagonista era tataranieta de Antonio Guerrero (séptimo hijo de los fundadores), poseedor del mayorazgo denominado El Grande y de Francisca de Torres Avilés, bisnieta de Juan Guerrero Dávila y Torres y María de Castilla Altamirano, nieta de Antonio Guerrero y Castilla y Ana María de Estupiñán Cales, e hija de José Mateo Guerrero Dávila Estupiñán y Lorenza Fernández del Corral. Fernández de Recas (1965, pp. 56-57). Su dote fueron más de 370000 pesos. De la importancia de su herencia nos da cuenta el pleito que hubo por ella, cuyos detalles podemos conocer a través de las obras de Nolasco de Herrera (1710); Lugo (1710); y Ordaz (1710). Más datos sobre este mayorazgo y sus protagonistas en Ladd (2006); Laviada Arrigunaga (1984); y Artís Espriu (1994).

${ }^{27}$ Aunque con algunos problemas, como puede verse en la "Consulta sobre que se declare perpetuo el título de Marqués de Villar del Águila en que ha sucedido Juan Antonio Urrutia, sin embargo del reparo puesto de la Secretaría" (AHN, Consejos, 4494, A.1738, exp. 7). Recordemos el problema surgido en época de Carlos II sobre los títulos vitalicios y su conversión, ya comentado anteriormente, que se terminó solucionando años después (23 de junio de 1741), con el "Certificado de carta de pago de media annata en 16 de junio por don Juan Antonio de Urrutia Arana y Guerrero [obsérvese el uso del nombre del mayorazgo de su esposa], tocante a la sucesión de doña María Pérez de Inoriza, su abuela, en el título de Marquesa de Villar del Águila, por muerte de su hijo el Marqués don Juan de Urrutia; y a la del mencionado don Juan Antonio de Urrutia Arana y Guerrero, por muerte de la citada doña María su abuela" (AHN, Consejos, 51586, exp. 1).

${ }^{28}$ AHN, Órdenes Militares. Caballeros-Alcántara, exp. 1534. En este interesante expediente se describen las armas familiares, las de Urrutia dicen los testigos y comisionados que son "un escudo de armas grande, que estaba a la esquina de la casa, el cual tiene dos cuarteles, y 
después de manera provisional a Querétaro, donde fue el responsable de la construcción del gran acueducto de la ciudad (1726-1738). Murió el 29 de agosto de 1743, en la calle de San Felipe Neri, en la ciudad de México, y fue enterrado en la misma ciudad en la iglesia del convento de religiosos descalzos de San Diego.

Al no tener hijos dejó la mayor parte de su fortuna para obras de caridad $^{29}$ y designó como sucesor al hijo mayor superviviente que su hermana mayor, María, tuvo con Sebastián Fernández de Jáuregui, ${ }^{30}$ Juan Antonio Fernández de Jáuregui y Urrutia (nacido en Menagaray en 1699), casado desde 1720 con María Aldama y Ayala, siempre con la condición de que debía irse a vivir a México, pero el interesado decidió quedarse en España y mandar a México a uno de sus hijos, que sería quien tomaría posesión de los bienes de su tío abuelo, y así continuaría la línea de los marqueses del Villar del Águila en el virreinato de Nueva España, ${ }^{31}$ y terminarían fijando su residencia definitiva en Querétaro. ${ }^{32}$

en el uno y principal se divisa una cruz al modo de Habito de Calatrava con ocho aspas, que dixeron estar en campo roxo y la cruz en campo dorado, que dicho escudo por deposición de los testigos es por el apellido Urrutia; y al lado siniestro hay otro cuartel en el escudo con un águila en campo que parece de plata, y según afirman los testigos, es del apellido Inoriza. Y continuando el reconocimiento de armas, hallamos otro escudo dibuxado en la pared, siendo su cuartel principal un árbol en campo de plata con dos leones, que parece que dicho cuartel toca a el apellido Arana, por deposición de los testigos; y el segundo cuartel es un niño en campo roxo, y toca a el apellido Chavarri”. Al final se dice que los citados comisionados "pintan y laminan las armas" con el fin de agregar el dibujo al Expediente, pero este dibujo ha desaparecido. Con estos datos se puede comparar la descripción que de las armas de los Urrutia y Arana hacen los testigos y comisionados en 1698 con la de nuestra certificación de armas de 1752, con las que tienen algunas diferencias; por ejemplo, en las de los Urrutia las panelas no se citan en 1698, mientras que las aspas desaparecen en 1752, pasando a rodear las armas de los Arana, que además añaden las fajas ondeadas en campo de plata, y cambian las especies de los animales (leones por lobos). Más datos sobre estas armas de los Urrutia y Arana en Ramírez Montes e Iturrate (1979, pp. 38-40 y 66-68).

${ }^{29}$ Mientras el mayorazgo Guerrero, perteneciente a su mujer, pasó a los familiares de ésta cuando ella murió el 20 de febrero de 1754 .

${ }^{30}$ A finales de la década de 1710 llegó a México el mayor de los hijos del citado Sebastián, llamado Sebastián Antonio (n. 1691), que se convertía así en presunto heredero de su tío, y allí murió soltero en 1740 .

${ }^{31}$ A pesar de no acudir a Nueva España, él y sobre todo su mujer, que le sobrevivió muchos años, usaron en la documentación el título Marquesal, como puede verse en la solicitud para viajar a Indias de su hijo menor, Juan Antonio Ángel (AGI, Contratación, 5498, N. 71, 9 de diciembre de 1756).

32 El primero en acudir a México fue Manuel Fernández de Jáuregui Urrutia y Aldama, en quien su padre renunció a los derechos de herencia sobre el mayorazgo del Marqués de Villar del Águila, como se dice expresamente en los documentos que aporta para solicitar 
Es ahora cuando tenemos que hablar de nuestro protagonista, Joseph (Antonio) Fernández de Jáuregui y Urrutia, hermano menor del anterior, e hijo de Sebastián Fernández de Jáuregui y Ojirando (natural de Menagaray, 1659-1742) y de María Urrutia y Arana (natural de Llanteno, 1681-1720), casados en 1681. El hijo mayor superviviente de este matrimonio, Juan Antonio, se hizo cargo de la herencia paterna (1742) y sus hijos de la que su tío Juan Antonio de Urrutia les había dejado en México (1743). Entretanto el hermano menor, Joseph Antonio (nacido en Menagaray el 6 de septiembre de 1703) pasó joven a México para servir a la Corona junto a su poderoso tío, estableciéndose en Querétaro, donde se encuentra durante las obras del famoso acueducto, siendo uno de los hombres de confianza del marqués, que fue padrino de una de sus hijas (a la que hizo un importante

viajar a Nueva España para "posesionarse" de los bienes de dicho mayorazgo, por ser una de las cláusulas del mismo que en quien recaiga haya de pasar a residir en la ciudad de México, y que, si esto no se cumplía en cinco años, el mayorazgo debía pasar al inmediato sucesor (AGI, Contratación, 5488, N. 3, R. 9, febrero de 1746). Manuel murió soltero antes de finales de 1750, y le sucedió en el título su hermano Sebastián Benito, caballero de la Orden de Alcántara (1753) (AHN, Órdenes Militares. Caballeros-Alcántara, exp. 761, expedientillos N. 14559), quien solicitó poder viajar a México para hacerse cargo de la herencia, que se encontraba en la ciudad de Santiago de Querétaro (AGI, Contratación, 5495, N. 1, R. 13, mayo de 1753). También murió soltero Sebastián, de hecho tenemos un poder donde se autodenomina "Juan Sebastián de Urrutia Fernández de Jáuregui y Aldama, Caballero de Alcántara y Marqués del Villar”, informando de su origen (lugar de Menagaray, Tierra de Ayala) y vecindario (en Querétaro) y declarando que "he sido poseedor del mayorazgo, como también en el Título de la Villa del Villar del Aguila" y diciendo que le debe suceder en ellos "mi hermano legítimo Don Juan Antonio Fernández de Jáuregui y Aldama, que hoy reside en los Reinos de Castilla", y lo firma en Querétaro a 2 de abril de 1755. Fernández de Recas (1965, p. 271). Cumpliéndose la previsión y sucediéndole en el mayorazgo y título su hermano menor Juan Antonio Ángel, quien solicita pasar a Indias para tomar posesión de su herencia (AGI, Contratación, 5498, N. 71, 9 de diciembre de 1756). En Nueva España casó con Ana María Rita de la Canal y Hervás, y fueron padres de Juan María Fernández de Jáuregui de la Canal, quien es el receptor de un informe de la Contaduría sobre confirmación del expresado título de Marqués (27 de abril de 1811), y carta de sucesión en el mismo para el dicho D. Juan María Fernández de Jáuregui, vecino de Querétaro (13 de junio de 1811) (AGI, Títulos de Castilla, 12, R. 25). Tras la Independencia de México, el hijo y heredero del anterior, Juan José Fernández de Jáuregui y Díez, será gobernador del estado de Querétaro (1835-1837), muriendo en el cargo. Esta es la complicada historia de la sucesión de los marqueses de Villar del Águila, que creemos se detalla aquí por primera vez con datos de fuentes directas, y que pronto será objeto de un trabajo monográfico donde se tratará no sólo la sucesión genealógica, sino también la obtención de las oficiales cartas de sucesión, la posesión judicial de los bienes del mayorazgo (que por uso consuetudinario eran equiparables a las cartas de sucesión), las renuncias, las autorizaciones temporales de uso del título, etcétera. Sobre las importantes relaciones con el País Vasco, véase Benavides Martínez (2015), quien añade amplia bibliografía sobre el tema. 
legado testamentario), y la nombró albacea en su testamento, fechado el 18 de noviembre de 1742. Hizo también Joseph un buen matrimonio casándose con María Gertrudis Josefa de Villanueva y Freyre (m. 1773), miembro de una rica e ilustre familia de Zacatecas. ${ }^{33}$ Fue caballero de la Orden de Alcántara (1752), ${ }^{34}$ gobernador y capitán general del Nuevo Reino de León (1731-1740), donde tuvo que hacer frente a la rebelión de los indios chichimecas; propuso la conquista del Seno Mexicano (territorio de Texas y Tamaulipas) y fue juez de residencia del gobernador de Texas (1737). De él nos quedan importantes textos sobre las provincias que gobernó o visitó. Su hijo Juan Antonio, nacido en Santiago de Querétaro, fue capitán de Dragones del Regimiento Provincial de Caballería Ligera de Querétaro y caballero de la Orden de Santiago (1779). ${ }^{35}$ Desconocemos la fecha de su muerte, pero sabemos que Joseph Antonio Fernández de Jáuregui y Urrutia estaba vivo en 1752, cuando en Madrid se realizó por su expresa petición esta certificación de armas que estamos comentando, y que casi seguro estaba relacionada con la tramitación de su expediente para ser nombrado caballero de la Orden de Alcántara, demostrando con ella la nobleza de sus cuatro apellidos y detallando sus armas; y ya había muerto cuando se iniciaron las pruebas para formar el expediente de concesión del hábito de la Orden de Santiago para su hijo. ${ }^{36}$

Por tanto, podemos suponer que, tras servir durante años a la Corona y conseguir una buena posición en México, nuestro protagonista buscó consolidar aún más su posición social; aunque sus relaciones familiares eran muy importantes quería ser reconocido por sí mismo, y por ello

${ }^{33}$ Hija de Juan Esteban de Villanueva (natural del Valle de Gordejuela, en Vizcaya) y de Justa Freire de Somorrostro (natural de Zacatecas), hija del capitán Tomás Freire de Somorrostro (originario de La Coruña), que fue corregidor de Zacatecas durante cinco años (juicio de residencia en 1686) y Caballero de Santiago (1684) (AHN, Órdenes MilitaresCaballeros-Santiago, exp. 3145), casando en esa ciudad minera con una rica heredera, Gertrudis de Bolívar y Mena, hija del capitán Luis de Bolívar y Mena, factor y oficial de la Real Hacienda y Caja de Zacatecas, y de su mujer María de Manjárrez; siendo luego él mismo factor, contador, juez y oficial real de las Cajas de Zacatecas. Más datos en el Testimonio de méritos de su hijo, el Licenciado Thomas Freire de Somorrostro y Bolívar, presbítero, comisario del Santo Tribunal de la Inquisición de Zacatecas y abogado de las Reales Audiencias, fechado el 9 de septiembre de 1723 (AGI, Indiferente General, 218, N. 111).

${ }^{34}$ AHN, Órdenes Militares, expedientillos, N. 14558 (fechado en agosto de 1752).

35 AHN, Órdenes Militares, expedientillos, N. 8214 y N. 18325; y exp. 2324.

${ }^{36}$ AHN, Órdenes Militares, expedientillos, N. 8214. Hay una certificación fechada en la ciudad de Santiago de Querétaro el 11 de septiembre de 1775 que indica que sus padres ya estaban muertos en este momento. 
quiere legar a sus descendientes esta certificación de armas, que encuadernará como luego veremos para que perdure y sirva de memoria de sus ilustres antepasados.

Gracias a la documentación conservada en la Sección de Órdenes Militares del Archivo Histórico Nacional de Madrid ${ }^{37}$ sabemos que Joseph Antonio recibió la merced de un hábito de orden militar (decreto de 17 de febrero de 1748) por "los méritos que adquirió siendo Gobernador del Nuevo Reyno de León en Nueva España”, y por los mismos años se concedió a su sobrino Manuel, marqués de Villar del Águila, la "merced de hábito en la Orden de Alcántara”, pero como falleció antes de terminar la tramitación, el rey decidió por decreto de 26 de febrero de 1751 "que la referida merced que tenía concedida al difunto marqués de Villar del Águila se entienda hecha a favor de su hermano y sucesor en el título, don Sebastián de Jáuregui y Urrutia”.

Las dos mercedes de hábito de Alcántara, para Joseph Antonio y su sobrino Sebastián, nuevo marqués de Villar del Águila, se tramitaron con la misma fecha (Buen Retiro, 4 de agosto de 1752) y fue este último el que se encargó de todas las gestiones en Madrid. ${ }^{38}$ En las pruebas presentadas para el primero se incluyen las certificaciones de bautismo de los hermanos Juan Antonio (padre de Sebastián) y de Joseph Antonio, ${ }^{39}$ así como los testamentos de sus padres, María de Urrutia (2 de febrero de 1717) y Sebastián Fernández de Jáuregui ( 9 de marzo de 1742), donde se cita a sus tres hijos varones; ${ }^{40} \mathrm{y}$ una genealogía donde aparecen sus padres y abuelos paternos y maternos, firmada y avalada por Sebastián Benito, como sobrino carnal, hijo de un hermano del "pretendiente". Todo ello se hizo durante el verano de 1752 y fueron admitidas como pruebas en el Consejo de Órdenes el 9 de octubre de 1752, y sin duda se aportaría también la certificación de armas, fechada en Madrid a 10 de octubre de 1752, un bastián).

${ }^{37}$ AHN, Órdenes Militares, expedientillos, N. 14558 (Joseph Antonio) y N. 14559 (Se-

${ }^{38}$ Sobre la concesión de hábitos y sus trámites administrativos es fundamental el trabajo de Álvarez-Coca González (1993, pp. 277-297), donde se explica con claridad todo el proceso administrativo para ratificar la merced real, la presentación de pruebas, la profesión, etcétera, y sobre la importancia de recibir un hábito en esta época y los entresijos burocráticos que conllevaba, podemos ver la obra de Postigo (1988).

${ }^{39}$ Ambas tuvieron lugar en la iglesia de San Pedro de Menagaray, la primera el 8 de enero de 1699 y la segunda el 6 de septiembre de 1703.

${ }^{40}$ Sebastián, el que murió en México en 1740; Juan Antonio, y Joseph Antonio, además de dos hermanas. 
documento que, sabemos, exigía la Orden de Alcántara como complementario a las pruebas genealógicas. ${ }^{41}$ De forma paralela y en las mismas fechas, Sebastián tramitó sus propias pruebas para recibir el hábito, y el Consejo ordenó el 26 de febrero de 1753 despachar el título de Caballero de la Orden de Alcántara, tanto para Joseph Antonio como para Sebastián. El segundo pagó el 9 marzo de 1753 los 131.250 maravedíes (350 ducados) ${ }^{42}$ por los servicios de montado y galeras, mientras su tío debió abonar “900 ducados de vellón, que valen 337.500 mrs de la propia moneda que importan los servicios de montado y galeras, y la licencia para profesar en Indias" el 31 de marzo de $1753 .{ }^{43}$

Tras todos estos trámites, ambos ya eran de forma efectiva caballeros de la Orden de Alcántara, y Sebastián decidió viajar a México para hacerse cargo de su herencia, solicitando para ello el preceptivo permiso (mayo de 1753), y debió llevar consigo tanto los títulos de caballero de Alcántara que acababa de conseguir como la certificación de armas de su tío Joseph Antonio, que le entregaría en la ciudad de Santiago de Querétaro, donde los documentos dicen que era residente Joseph Antonio, y a donde tenía que acudir Sebastián a reclamar su herencia, como dice en su solicitud de viaje.

Tras detallar la historia de este documento, sus características tipológicas y el motivo de su realización, nos queda una pregunta más sobre él, ¿̇llegó ya encuadernada la certificación de armas y por tanto el trabajo fue hecho en Madrid, o el propietario de la misma la hizo encuadernar en Nueva España?

${ }^{41}$ Vargas-Zúñiga y Mendoza (2017, p. 252) comenta que, además de la hidalguía de sangre de los ascendientes del solicitante, la Orden de Alcántara exigía la prueba de armas de los cuatro abuelos, como queda reflejado en el título xiII de las Definiciones de la Orden y Cavallería de Alcántara. Madrid: 1576.

${ }^{42}$ En estos años el ducado era ya una moneda imaginaria que servía para datos contables; su valor era de 375 maravedís.

${ }^{43}$ Esta era la última fase del expediente, que se inicia cuando el caballero recibe formalmente el título y que termina cuando profesa, es decir, cuando se hace un acto solemne en el cual es armado caballero y recibe el hábito. Esta ceremonia tenía que hacerse, teóricamente, en las cabeceras de cada orden, pero dada la dispersión geográfica de la monarquía, el soberano concedía normalmente una dispensa para poder tomar el hábito en otro lugar. Ahora bien todavía quedaba una última formalidad, un vez recibido el hábito, el caballero estaba obligado a cumplir un año de noviciado, y durante este tiempo debía servir unos meses en las galeras del rey y residir cierto tiempo en el convento de la orden, pero en esos años tales exigencias eran una mera formalidad, que se suplía con el pago de ciertas cantidades de dinero por "relevación de montados y galeras", como vemos en el caso de nuestro protagonista. Más datos en Álvarez-Coca (1993, pp. 295-297). 


\section{OTROS DOCUMENTOS SIMILARES}

Una vez que hemos entendido la naturaleza administrativa del manuscrito es importante insistir en el hecho mismo de que en esta investigación se estudia un documento, el cual en muchos casos caería en la categoría de recurso de archivo, que usualmente carece de encuadernación; pero en este caso, dicho documento tiene la característica de que por su relevancia histórica y administrativa para el recipiendario y su familia requería de una estructura (encuadernación) que garantizase su correcta conservación en la familia propietaria del mismo y que, además, ésta aludiera a esa relevancia.

Dicho lo anterior, no sería extraño pensar que la certificación de armas pudo ser encuadernada en México, ya que también ahí se emitieron diversos documentos similares al que hemos comentado; y aunque el objetivo de este trabajo no es dar cuenta de cada uno de ellos, sirva de ejemplo mencionar algunos, todos con encuadernaciones muy significativas. ${ }^{44}$ Uno de los más antiguos, que actualmente se encuentra en la Library of Congress, es Una carta confirmatoria de hidalguía, la cual es un manuscrito emitido en ciudad de México, datado entre 1597-1600 y es el registro del testimonio ofrecido por Sebastián Vizcaíno (1550?-1615), para demostrar la condición de nobleza de su mujer, Magdalena Martínez Orejón, y del hermano de ésta, Francisco Martínez Orejón. ${ }^{45}$ Del mismo año tenemos la "Carta ejecutoria de hidalguía", patente de nobleza de Antonio de Nava de Larma publicada por Pedro Balli y que al día de hoy se encuentra en The Morgan Library, ${ }^{46}$ otro ejemplo es la "Certificación de la nobleza de D. Juan Gómez Rodríguez de Pedroso Bárcena y Soria”, documento bajo el resguardo de la Universidad de las Américas de Puebla, que fue elaborado a finales del siglo XVIII, en $1792 .{ }^{47}$

${ }^{44}$ Aunque no los tratamos de forma específica, este trabajo puede servir para revisar la tipología documental con la que están catalogados documentos similares al estudiado, que existen tanto en la biblioteca del Museo Franz Mayer de la ciudad de México, en el Fondo Reservado de la Biblioteca “Rafael García Granados” del Instituto de Investigaciones Históricas de la UnAM, o en la Hispanic Society de Nueva York.

${ }^{45}$ Vizcaíno (1600).

${ }^{46}$ Carta ejecutoria de hidalguía (1597). The Morgan Library \& Museum. www.themorgan.org/manuscript/159996 (consultado el 3 de septiembre de 2017).

${ }^{47}$ Ejecutoria de hidalguía. Certificación de la nobleza de D. Juan Gómez Rodríguez de Pedroso Bárcena y Soria (1792). Blog UDLAP. blog.udlap.mx/blog/2011/05/ejecutoria-de-hidalguia (consultado el 3 de septiembre de 2017). 
No obstante, en la mayoría de los casos y en específico respecto del manuscrito que analizamos, la información acerca de la fecha y el lugar de factura, no son datos suficientes para consignar el origen de la encuadernación, dado que ésta puede o no ser original del documento que resguarda. En este sentido y en referencia a las técnicas constructivas y decorativas, la datación es igualmente complicada, aunque si bien existen elementos tales como hierros y ruedas que pueden ayudar a designar el encuadernador o el taller, también es verdad que muchos de estos utensilios se prestaban o imitaban; por tanto, el simple hecho de definir un esquema decorativo, entendido éste como un estilo artístico, por ejemplo el renacentista, o un tipo de encuadernación, como pueden ser las de legascon, no define el origen de la manufactura de la encuadernación. Por otro lado, existen elementos tales como firmas, anagramas, etiquetas y ciertos hierros, que sí pueden especificar la autoría y el origen de una encuadernación.

Debido a eso, es preciso un análisis minucioso que describa las técnicas constructivas y decorativas, así como los materiales y herramientas observados en la confección de la encuadernación, ya que la información obtenida puede ayudar no sólo a datar la encuadernación, sino también, a contextualizar históricamente a la propia certificación.

\section{LAS ENCUADERNACIONES DE DOCUMENTOS ADMINISTRATIVOS}

Como ya se mencionó en el apartado anterior, al hablar de una certificación de armas, o de una ejecutoria de hidalguía, así como de cualquier otro manuscrito similar, nos estamos refiriendo a materiales que por su relevancia administrativa, requerían de una encuadernación que garantizara su conservación y que ésta denotara la importancia del documento. Por lo tanto, la encuadernación en documentos administrativos y de archivo no es algo raro, así lo ejemplifican los libros de cuentas en notarías, o bien, los libros de obra y fábrica en archivos de cabildo como los de Toledo en España, que cuentan con encuadernaciones igualmente elaboradas, caracterizadas por presentar una solapa que se superpone a la tapa anterior, y que están hechas de pergamino, con costuras expuestas, empleando decoración de rosetones bordados en las tapas y solapas (figura 4). 
En cuanto a la materialidad de las llamadas cartas ejecutorias de hidalguía, títulos, privilegios y documentos similares, hay que decir que al extender su contenido cambiaron el antiguo formato de hoja suelta por el de cuadernillo. Este libro-cuadernillo, relativamente grueso, está realizado en pergamino y de igual manera, si antes era puesto un sello de plomo pendiente, sujeto a una plica que reforzaba la parte inferior del documento, en el nuevo formato, el sello de plomo pende de unas cuerdas que recorren todo el lomo del libro.

Por tanto, la propia estructura de la encuadernación adquiere valor documental, al ser una forma de testificar la riqueza del demandante, puesto que la idea de la excelencia se cifraba en el aspecto exterior ${ }^{48}$ y en muchas de estas encuadernaciones se puede apreciar su nivel técnico en el que se distinguen diferentes modalidades artísticas, con el empleo de materiales nobles que hacen gala de la propia nobleza del propietario del manuscrito en cuestión. Aunque esta clase de documentos ya existía en el siglo xv, prácticamente aparecen sin encuadernar, o con un pergamino simple como protección, escritos en cuadernillos de pergamino, con adornos en sus iniciales o con alguna miniatura. Por lo tanto, no cabe duda de que la Edad Media es fundamental como fuente de inspiración de las ejecutorias posteriores tanto en su contenido como en su caligrafía y en muchos casos también en su encuadernación.

Así igualmente otros documentos, al ir modificando su materialidad y al integrar más información en su contenido, alteraron su estructura pasando de un folio a uno o varios cuadernillos. Afortunadamente en España existen aún muchos de estos ejemplos de notable calidad en su encuadernación; por mencionar algunos, citaremos tres: ${ }^{49}$

1. El primero es una "Prueba de sangre de don Francisco Bernabé Tortosa y Pnedés", ${ }^{0}$ de 1789 y estilo neoclásico, con encuadramiento de tres ruedas doradas, entero en piel roja, con sello de plomo pendiente.

${ }^{48}$ Ibidem, p. 3. Ruiz García (2006), a quien seguimos aquí para explicar el contenido y la estructura de estos documentos.

${ }^{49}$ Los ejemplos citados han sido elegidos sólo por la razón de que son encuadernaciones con un estilo artístico definido. Las fotografías han sido tomadas del libro El documento pintado: cinco siglos de arte en manuscritos, del cual a continuación se desglosa la cita pertinente de cada uno de los ejemplos.

${ }^{50}$ El documento pintado (2000, pp. 67-68, figs. 37 y 38). 
2. El segundo ejemplo lo tenemos en un "Privilegio de infanzonía de Juan Sebastián de Yriarte y Larramendi", ${ }^{51}$ del año 1643, que luce una encuadernación del siglo XVII, entera en piel de becerro con hierros dorados dispuestos indistintamente en los planos de las tapas.

3. Y por último aludiremos a "La Sentencia y Carta ejecutoria de Gaspar Dorantes, vecino de la Villa de Baltanás sobre su hidalguía", ${ }^{52} \mathrm{de}$ 1555 y de estilo abanicos, entera en piel de becerro, su estructura decorativa está enmarcada por un encuadramiento de doble hilo, resaltando en los ángulos internos los abanicos en $90^{\circ}$ y en el centro de las tapas un abanico de $360^{\circ}$, las varillas de los abanicos con elementos fitomorfos, todo ello decorado con la técnica del dorado (figura 5).

\section{LA ENCUADERNACIÓN Y SU CONTEXTO HISTÓRICO EN MÉXICO}

Antes de describir formalmente la encuadernación que ostenta el manuscrito que nos ocupa en este estudio, conviene hacer un brevísimo repaso del devenir histórico del "arte de la encuadernación" en México, con el objetivo de ofrecer un panorama que ilustre el desarrollo de la encuadernación como objeto.

En el México virreinal, debido a la situación de mestizaje, se dieron circunstancias tales como la evangelización y tiempo después la creación de instituciones académicas y bibliotecarias, mismas que propiciaron que el libro no sólo fuese necesario para propagar la fe, sino también para fines de tipo educativo y administrativo, e incluso recreativo. Por tanto, sin importar cuál fuera su fin, el libro se convirtió en un objeto mercante. Este hecho nos revela que, tal y como ya sucedía en la época precolombina, tanto al libro como a los códices se les atribuirían cualidades de perdurabilidad y testimonio fiel para registrar y respaldar los acontecimientos de la vida cultural y administrativa. Evidentemente, todo ello precisaba de un mecanismo de autogestión para no depender de la importación de libros que eran traídos desde la península y así paulatinamente lograr autoabastecerse.

${ }^{51}$ El documento pintado (2000, pp. 216-217).

${ }^{52}$ El documento pintado (2000, pp. 164-165). 
Por tanto, para la producción de libros eran necesarios por lo menos tres elementos: papel, imprenta y talleres de encuadernación. Como datos fehacientes, sabemos de la creación del primer molino papelero en Culhuacán entre los años 1576 y 1580,,$^{53}$ en cuanto a la instauración de la imprenta, existe un protocolo del escribano don Alonso de la Barrera, que es un contrato entre el alemán Juan Cromberger y el italiano Juan Pablos, firmado en Sevilla el 12 de junio de 1539 para el traslado y la instalación de la primera imprenta formal con tipos móviles en la ciudad de México. ${ }^{54}$ Estos dos primeros aspectos ya resueltos nos hacen suponer que, si en México se imprimía, también se encuadernaba; y aunque el orden de los procesos de producción no es un objeto de análisis para esta investigación, cabe mencionar que según la hipótesis propuesta por la doctora Marta Romero, ${ }^{55}$ los libros asimismo venían, muchos de ellos, "desnudos” y otros más encuadernados pero maltrechos por el largo viaje. Por ello tuvieron que ser reparados y en determinados casos, encuadernados, con lo cual quedaría solucionado el tercer aspecto para la producción de libros. Lo anterior nos lleva a presumir que en el Nuevo Mundo primero se encuadernó y después se imprimió, porque la necesidad de mantener los escritos en buen estado fue anterior a la llegada de la imprenta. De hecho, hay registro de un taller de encuadernación dentro del Colegio Imperial de Tlatelolco, abierto desde 1536, que estuvo a cargo de franciscanos. Ahí se enseñaba a los jóvenes indígenas gramática española y latina, música, historia sagrada y universal, literatura clásica y filosofía. Además, la presencia de algunos maestros indígenas permitió a los frailes y estudiantes adentrarse en la farmacología tradicional, la historia, el calendario, los antiguos códices y los textos que contenían la sabiduría moral de Mesoamérica, y en ese centro educativo los indígenas asimismo aprendieron y ejercieron la encuadernación.

Igualmente se sabe que en los conventos de las misiones franciscanas se encuadernaba todo tipo de minucias librarias como gramáticas, catones y catecismos. Además, a través de las biografías de los impresores, libreros y bibliófilos de la época que arribaron a México, se ha sabido que muchos de ellos conocían de encuadernación, tanto de su manufactura como de su identificación. Tal es el caso de Pedro Balli, quien llegó a México en 1569

\footnotetext{
${ }^{53}$ Montellano Arteaga (2009).

${ }^{54}$ Pompa y Pompa (1988, p. 15).

${ }^{55}$ Romero (2016).
} 
y al tiempo de solicitar su pasaje declaró su profesión como librero y llevaba consigo algunos libros y útiles de encuadernación, ${ }^{56}$ y también fue reconocido como un notable impresor.

Por último, es importante mencionar que de los primeros personajes, si bien no eran encuadernadores, sí conocían las características de los distintos estilos y tipos de encuadernaciones. Éstos fueron Nicolás León y Manuel Romero de Terreros. Nicolás León publicó en 1889 "Lo que se encuentra en las pastas de los viejos libros de México". Él mismo mantuvo una relación epistolar con Manuel Romero de Terreros, y gracias a todas las referencias que Nicolás León le proporcionó, Manuel Romero de Terreros publicó su artículo "Las encuadernaciones artísticas mexicanas" en el año de 1943.

\section{LA ENCUADERNACIÓN \\ DE LA "CERTIFICACIÓN DE ARMAS"}

El estudio de la encuadernación implica un análisis minucioso y estructurado, para lo cual es necesario establecer un instrumento que estructure el proceso descriptivo y que a la vez sirva de herramienta de consulta.

El análisis formal de la encuadernación es una tarea sistemática que abarca distintos niveles no jerárquicos, pero que requieren una estructura determinada con el fin de que la información obtenida del estudio pueda ser clasificable e interpretada, y que si además dicha investigación fuese vertida en un catálogo pertinente, ésta fuera fácilmente indizada y recuperada.

La estructura propuesta para del análisis consta de tres apartados, en el primero se registran los "Datos de identificación" como son signatura topográfica, la descripción bibliográfica, en donde únicamente se refiere el título y el autor del libro que resguarda la encuadernación.

El segundo apartado se dedica a describir la encuadernación: son los "Datos propios de la encuadernación", como el tipo de encuadernación, el encuadernador, el periodo de confección, las dimensiones, las procedencias, los materiales utilizados, las técnicas de construcción y decoración, los elementos heráldicos y marcas de pertenencia o de referencia, así como el estado de conservación.

${ }^{56}$ Pedro Balli. Primeros Libros de las Américas. primeroslibros.org/about_printers. html?lang=es\&by=balli (consultado el 27 de octubre de 2017). 
Por último, el tercer apartado está destinado para las "Notas" en donde, de ser necesario, se consigna cualquier información adicional que no se haya contemplado en la descripción de la encuadernación, como el precio, la información sobre exposiciones, los elementos coincidentes con otras encuadernaciones, etcétera.

A continuación, y siguiendo los apartados indicados, presentamos el estudio de la encuadernación:

Datos de identificación

Manuscrito 10158, de la Biblioteca Nacional de México, que tiene por título "Carta ejecutoria de la Familia Fernández de Jáuregui, a cargo de Joseph Fernández de Jáuregui (el demandante)”.

Datos propios de la encuadernación

Tipo de encuadernación

Se trata de una encuadernación artesanal con acabados artísticos, presuntamente original al documento.

\section{Encuadernador}

En este caso, el encuadernador o taller de encuadernación puede identificarse mediante distintos mecanismos, el más común es la impronta dorada con el nombre del encuadernador o anagrama a pie de lomo, asimismo en otras ocasiones puede aparecer esta firma en la ceja de la tapa anterior, o bien una etiqueta que indique incluso el año en que se ha confeccionado la encuadernación. Otra manera en que puede establecerse la autoría es mediante la identificación de hierros típicos de un encuadernador empleados en la ornamentación. Sin embargo, dado que esta encuadernación carece de anagramas al pie del lomo, o elementos de identificación de la autoría, como etiquetas o leyendas, el encuadernador no ha sido identificado. 


\section{Periodo}

Es una encuadernación del siglo XVIII, definida así debido a que este tipo de documentos no podían encuadernarse en blanco, por lo que el periodo en el que se sitúa está determinado por la fecha en la que el manuscrito es validado, que en este caso corresponde al día 10 de octubre de 1752, fecha a partir de la cual pudo haberse encuadernado.

\section{Dimensiones}

En cuanto al formato, la encuadernación se corresponde con la nomenclatura de $1 / 4$ con unas dimensiones específicas, que son: $336 \times 216 \times 20 \mathrm{~mm}$. Cabe mencionar que en el caso del análisis de encuadernaciones, la medida que corresponde al espesor, es decir los $20 \mathrm{~mm}$, siempre es consignada debido a que proporciona con exactitud el grosor del libro y esta información puede ser útil para elaborar guardas o cajas de conservación, o bien para comparar el estado de conservación antes y después de un exceso de humedad.

\section{Procedencia}

En este apartado, suelen analizarse todas aquellas marcas observadas en cualquier parte de la encuadernación, como pueden ser emblemas, anagramas o escudos de armas, los cuales usualmente se encuentran plasmados en la ornamentación de las tapas, ya sea como motivo central o en las ruedas, formando encuadramientos. En este caso desafortunadamente no se aprecia ninguna marca de procedencia de ese tipo.

\section{Materiales utilizados}

Las tapas son de cartón, el lomo y las tapas están recubiertos con piel de color caoba, las guardas son de papel con diseños xilográficos en colores azul y amarillo. Para la costura se ha empleado cordel de fibra vegetal y el material utilizado para la decoración de las tapas es el pan de oro, y los cortes están teñidos con pigmento verde. 
El cuerpo del libro está integrado por distintos materiales. Tiene un primer cuadernillo de vitela y tela color rojo, mientras que el resto es de vitela; aunque al final, a manera de hoja de respeto, presenta una hoja de papel verjurado con filigrana de estructura tre mondi en la que se aprecia una cruz trebolada por cima, en el primer círculo una media luna, en el segundo una paloma y en el tercero el signo matemático menor (figura 6).

\section{Técnicas de construcción}

En cuanto a la parte externa, las tapas y el lomo forman una sola pieza mediante la adhesión de la piel (recubrimiento) con el cartón (material de las tapas), a su vez, esta estructura se une al libro mediante tres mecanismos que son: el encartonado sencillo, el cual consiste en que cada uno de los nervios se inserta en una perforación de la tapa, quedando el cabo de los nervios, por dentro de la misma; el risclado ${ }^{57}$ es la operación que se efectúa deshilachando el cordel de los nervios que se ha introducido en las tapas y sirve para lograr una mejor adhesión, evitando así que los nervios produzcan una protuberancia perceptible, a la vez de que se consigue una mejor unión del cuerpo del libro con las tapas; y el tercer mecanismo es otro proceso de unión de las tapas con el cuerpo del libro, mediante la adhesión de las guardas a las tapas (figura 7).

Y en cuanto a la parte interna, la costura que une los cuadernillos está realizada cuaderno a cuaderno, con un trazo de punto seguido sobre tres nervios sencillos. El lomo se ha redondeado y presenta una apariencia lisa.

Estructura decorativa

La estructura decorativa es simétrica, lo que significa que tanto en la tapa anterior como en la tapa posterior, el diseño de la decoración es el mismo. Éste consiste en dos encuadramientos, uno marginal y otro central, los cuales están unidos por los vértices y por el punto medio de cada una de

${ }^{57}$ Risclar es una operación que consiste en deshebrar el cordel haciendo que las fibras queden lo más finamente posibles, sin perder fuerza en su estructura para lograr una buena sujeción en el cartón de las tapas. 
las líneas del encuadramiento, mediante una rueda de motivos vegetales. En el encuadramiento marginal se resaltan los vértices externos con un pequeño florón, al igual que en el ángulo interno del encuadramiento central. Los hilos de ruedas que unen los encuadramientos tienen un pequeño florón a manera de mariposa, mientras que en el centro de las tapas se aprecia una composición en forma de rombo compuesta con un mismo hierro, es decir que se trata de un hierro de esquina o de $45^{\circ}$, que se dispone consecutivamente en la misma dirección y en la misma posición, partiendo del mismo punto; a esta composición la rematan, en las puntas norte y sur, dos florones (figura 8).

En cuanto a la decoración del lomo, ésta consiste en ruedas de motivos florales colocadas paralelamente de manera horizontal, acotando los nervios, y los entrenervios que se simulan presentan un pequeño florón central. La técnica decorativa aplicada en la ornamentación es el dorado (figura 9).

Por su parte, las guardas son xilográficas. El diseño que presentan se logra con una técnica que consiste en la impresión de una o más matrices de madera, las cuales son entintadas y la impronta que dejan es el diseño que se percibe, el cual en este caso es de tipo floral a dos colores, amarillo y azul, y con dos matrices. El diseño de las guardas imita los papeles franceses del siglo XviII con grandes motivos florales.

Elementos heráldicos y marcas de procedencia y de referencia

El libro presenta en el primer cuadernillo, en la hoja 1r, un escudo policromado perteneciente a la familia Fernández de Jáuregui-Ojirando-Urrutia y Arana; en la hoja 2r, el escudo con las grandes armas de la monarquía, así como también en el último de los cuadernos aparecen, en la hoja $35 \mathrm{v}$, la rúbrica y el sello de oblea del rey de armas Juan Alfonso Guerra Sandoval, y en la hoja 36r y v, las firmas de los escribanos públicos de la Imperial y Coronada Villa de Madrid y la certificación de Vicente Francisco Verdugo.

\section{Estado de conservación}

Se considera aceptable ya que únicamente presenta abrasión en los cantos y en la tapa anterior, desfloramiento de la piel y rasgaduras, además 
de tener las puntas ligeramente abiertas y falta de guardas volantes. ${ }^{58}$ De manera preventiva se recomienda consolidar pintas y conservarse en guarda de primer nivel, así como también una digitalización íntegra del documento para facilitar la consulta y evitar posibles daños.

\section{Conclusiones}

1. Cambio de nombre a certificación de armas. Después de todo lo comentado ha quedado probado que el documento estudiado no es una carta ejecutoria de hidalguía, sino una certificación de armas, por lo cual debería ser catalogado usando este término preciso que designa de forma inequívoca el contenido del mismo. Por lo anterior, también consideramos pertinente revisar la catalogación de documentos similares custodiados en otros fondos bibliográficos y archivísticos para comprobar que el nombre por el que se conocen defina realmente el contenido jurídico del manuscrito.

2. Vínculos familiares entre Castilla y México. Al estudiar la familia de la persona que solicitó el documento vemos una estructura que ya conocíamos, pero que aquí se aprecia con gran claridad. Muchas familias castellanas asentadas en México desde la época de la Conquista y con importantes mayorazgos y caudales tienen únicamente como herederas a mujeres, que en muchos casos se casan con personajes llegados de la península para servir a la Corona en el virreinato, y se quedaron en las Indias tras contraer matrimonio con las ricas herederas; en ocasiones era un cláusula de los mismos el residir allí (e incluso cambiar su nombre para mantener el del antiguo mayorazgo), y se solicitaba a sus parientes en Castilla que les mandasen a jóvenes de su familia para heredarles y asentarse en México. En este caso las familias que fueron a México estaban radicadas en zonas concretas del actual País Vasco,

${ }^{58}$ Para poder definir el grado de deterioro en una encuadernación se establecen tres categorías: A) Óptimo: cuando los deterioros son mínimos, casi imperceptibles, por ejemplo: suciedad, abrasión mínima en cantos o puntas, etcétera. B) Aceptable: cuando presenta deterioros notables pero que no impiden la consulta del libro, por ejemplo: rasgaduras en recubrimiento, faltantes en las guardas, puntas abiertas, etcétera. C) Reservado: cuando los deterioros inciden directamente en el manejo del libro e impiden su consulta, por ejemplo: tapas desprendidas, costura colapsada, infección por microorganismos, etcétera. 
lugar que fue una de las mayores zonas de emigración hacia las Indias y en concreto hacia Nueva España.

3. Diferencias en las armas en su descripción. Las descripciones específicas de las armerías han pasado por diversas etapas, y las piedras armeras, los sellos, los reposteros y otros soportes (cerámica, joyas, platería, etcétera) pueden mostrar diversos aspectos diferentes a los especificados en la certificación de armas; es algo relativamente normal en esta época y que no debe extrañarnos, por lo cual hacemos referencia a los mismos en una nota, pero sin darle mayor importancia.

4. Encuadernación mexicana o madrileña. Resulta aventurado determinar el origen de la encuadernación sin tener evidencias certeras que lo señalen. No obstante a partir del aspecto estético se pueden postular dos hipótesis.

Primera hipótesis: que, a juzgar por la fecha en que se redactó y firmó el documento, se trate de una encuadernación madrileña, puesto que podría pensarse que, a sabiendas de que el manuscrito viajaría rumbo a México, se decidiera encuadernarlo, aunque fuese de manera austera, con el objetivo de ser al mismo tiempo un mecanismo de salvaguarda del documento, manteniéndolo unido y protegido hasta el momento de ser almacenado en un baúl, y lograr así soportar la travesía del viaje. ${ }^{59}$

Por otra parte, la segunda hipótesis sugiere que, dado el aspecto estético de la encuadernación, de acabados más bien rústicos, se trate de un documento que llegó a México plegado o enrollado pero desnudo, y que una vez en su destino, se mandó encuadernar. Por tanto se trataría de una de las primeras encuadernaciones realizadas en México.

A ambas teorías podríamos añadir que, para el siglo XVIII, en España ya se cuenta con notables encuadernadores, mismos que eran identificados por el empleo de anagramas, hierros distintivos o las propias firmas en improntas doradas; mientras que en México, no se tiene constancia del establecimiento de encuadernadores de alto prestigio provenientes de España y que desarrollaran ahí su labor. Ese hecho nos hace suponer que, a pesar de que en México ya se encuadernaba desde prin-

${ }^{59}$ Son varios los libros que refieren que se tiene constancia de la documentación que se encuentra en el Archivo General de Indias, de que muchos eran los cajones de libros que llegaban a Veracruz en México, desde el puerto de Cádiz, incluso hasta ya bien entrado el siglo XIX; ya fuera por deseo u orden de individuos comunes, instituciones o libreros comerciantes. Cfr. Gómez Álvarez (2011). 
cipios del siglo XVI, no existía una categorización de encuadernadores, de primera y segunda fila. Por tanto, para el encargo de encuadernaciones de este tipo se acudía a los talleres existentes.

Finalmente y como nota al margen, cabe mencionar que el hecho de no tener fe del establecimiento de encuadernadores de renombre no interfiere con la posibilidad de contar con encuadernaciones firmadas por encuadernadores de alto prestigio, ya que se han hallado en fondos antiguos de bibliotecas mexicanas libros con la firma de Antonio de Sancha, un notable encuadernador y librero del siglo XVIII, quien por razones de compra y venta mantuvo relación comercial con Felipe Zúñiga, impresor y librero de México.

\section{BibliografíA}

Álvarez-Coca GonzÁlez, M. J. (1993). La concesión de hábitos de caballeros de las órdenes militares: procedimiento y reflejo documental (s. xvI-XIX). Cuadernos de Historia Moderna, 14, 277-297.

ANDRÉs, G. de (1990). La biblioteca nobiliaria del cronista Juan Alfonso Guerra, rey de armas de Felipe V. Boletín de la Real Academia de la Historia, CLXXXVII, 373-402.

Artís Espriu, G. (1994). Familia, riqueza y poder un estudio genealógico de la oligarquía novohispana. México, Centro de Investigaciones y Estudios Superiores en Antropología Social (Colección Miguel Othón de Mendizábal).

Benavides Martínez, J. J. (2015). Los alaveses en Nueva España y la huella novohispana en Álava durante el siglo xviII. Revista Electrónica Iberoamericana, 9-2, url: https://www.urjc.es/images/ceib/revista_electronica/vol_9_2015_2/ REIB_09_02_JJ_Benavides.pdf (consultado el 14 de mayo de 2019).

Balli, Pedro. Primeros Libros de las Américas. primeroslibros.org/about_printers. html?lang=es\&by=balli (consultado el 27 de octubre de 2017).

Carta ejecutoria de hidalguía (1597). The Morgan Library \& Museum. www.themorgan.org/manuscript/159996 (consultado el 3 de septiembre de 2017).

Castrillón, A., R. P. fray (1744). Oracion funebre panegyrica, condigno honorifico llanto: con que la gratitud de la nobilissima ciudad de San Tiago de Queretaro sintio la muerte de su mas generoso bienhechor el Sr. D. Juan Antonio de Urrutia, Arana, Guerrero, y Davila, caballero del Orden de Alcantara, y marques de la Villa del Villar de la Aguila. México: en la Imprenta de la Viuda de D. Joseph Bernardo de Hogal. 
Ceballos-Escalera y Gila, A. de, marqués de la Floresta (1993). Heraldos y reyes de armas en la Corte de España. Madrid: Prensa y Ediciones Iberoamericanas.

Conde y DíAz-Rubín, J. I., y J. E. Sanchiz Ruiz (2008). Historia genealógica de los títulos y dignidades nobiliarias en Nueva España (vol. I). México: Universidad Nacional Autónoma de México, Instituto de Investigaciones Históricas.

El documento pintado: cinco siglos de arte en manuscritos (2000). Madrid: Ministerio de Educación y Cultura/Museo Nacional del Prado/Asociación para el Fomento de la Encuadernación de Arte.

Ejecutoria de hidalguía (2011). Blog de la Universidad de Las Américas Puebla. blog. udlap.mx/blog/2011/05/ejecutoria-de-hidalguia/ (consultado el 3 de septiembre de 2017).

FERnÁNDEZ De ReCAs, G. (1965). Mayorazgos de la Nueva España (vol. 10). México: Universidad Nacional Autónoma de México, Instituto Bibliográfico Mexicano. Frías Camacho, I. R. (comp.) (1994). El marqués don Juan Antonio de Urrutia y Arana, marqués de la villa del Villar del Águila, Ayuntamiento de Querétaro.

Gómez Álvarez, C. (2011). Navegar con libros: el comercio del libro entre España y México (1750-1820). México: Trama.

Gómez de Olea y Bustinza, J. (2005). La nobleza titulada en la América española. Madrid: Real Academia Matritense de Heráldica y Genealogía.

Guerra y Villegas, J. A. de (1693). Discurso histórico político sobre el origen y preheminencias de el oficio de heraldos, reyes de armas, feciales y caduceadores. En que se describen algunas noticias de lo que observavan los Reyes de Armas, assi en otros Reynos, Estados y provincias, como en los desta Monarquia Española, en quanto al exercicio, y practica de este Ministerio. Madrid: Imprenta Real por Mateo de Llanos y Guzmán.

Guillén Berrendero, J. A. (2009). Blasones y esmaltes: Don Juan Alfonso de Guerra y Sandoval y el oficio de Rey de Armas. En Las élites en la época moderna: la monarquía española (vol. 4, pp. 185-204). Coordinación de E. Soria Mesa, J. J. Bravo Caro y J. M. Delgado Barrado. Córdoba: Universidad de Córdoba.

Huidobro, J. M. (2015). La carta ejecutoria de hidalguía. Hidalgos en la historia. https://hidalgosenlahistoria.blogspot.it/2015/01/la-carta-ejecutoria-de-hidalguia_22.html (consultado el 3 de septiembre de 2017).

LADD, D. M. (2006). La nobleza mexicana en la época de la Independencia 1780-1826. Traducción de Marita Martínez del Río de Redo. México: Fondo de Cultura Económica (Colección Historia) (original en inglés publicado por la Universidad de Texas en 1976).

(1984). La nobleza mexicana en la época de la Independencia 1780-1826. México: Fondo de Cultura Económica. 
LAdrón de Guevara E IsASA, M. (2016). Los procesos de hidalguía en los Tribunales de la Corona de Castilla. Siglos XV al XVII. Madrid: Real Academia Matritense de Heráldica y Genealogía.

Ladrón de Guevara e Isasa, M., y A. Moreno Almárcegui (2016). La hidalguía en la Corona de Castilla, siglos XVII al XIX. Pamplona: Ediciones Universidad de Navarra.

Laviada Arrigunaga, I. (1984). Vida y muerte de un latifundio. México: Porrúa.

LoARCa CAstillo, E. (1993). El marqués de la Villa del Villar del Águila: don Juan Antonio de Urrutia y Arana. Querétaro: Coordinación de Publicaciones del Ayuntamiento.

Lohmann Villena, G. (1947). Los americanos en las órdenes nobiliarias (15291900) (2 vols.). Madrid: Consejo Superior de Investigaciones Científicas, Instituto Gonzalo Fernández de Oviedo (reedición, 1993).

Lugo, Felipe de (1710). Por Don Joseph Moctezuma Guerrero Davila, en el pleito que sigue con Doña Maria Guerrero Davila, Marquesa del Villar de la Aguila, y con Don Juan de la Cueva Guerrero Davila, y con Don Juan Francisco de la Cueva Guerrero Davila, sobre que se declare a su favor la propiedad de el Mayorazgo que fundaron Juan Guerrero de Luna y Doña Beatriz Gomez Davila su mujer, el año de 1589. Y consiguientemente se le adjudiquen los frutos de él, desde la muerte de Don Joseph Mateo Guerrero Davila, ultimo poseedor, que murió por Enero del año de mil setecientos nueve, sin dejar hijo, ni descendiente varon que conforme a la voluntad de los fundadores, y según las clausulas y vocaciones de la fundación le succediesee. México: en la Imprenta Nueva Plantiniana de Diego Fernández de León.

Martínez Cosío, L. (1946). Los caballeros de las órdenes militares en México. Catálogo biográfico y genealógico. México: Editorial Santiago.

Matilla, J. M. (2000). Símbolos de privilegio y objetos de arte. Los documentos pintados en la sociedad española del antiguo régimen. En El documento pintado cinco siglos de arte en manuscritos (pp. 15-21). Madrid: Ministerio de Educación y Cultura/Museo Nacional del Prado/Asociación para el Fomento de la Encuadernación de Arte.

Montellano Arteaga, M. (2009). Culhuacán: el primer molino de papel en América. Boletín de Monumentos Históricos, Instituto Nacional de Antropología e Historia, 16, 74-90. boletin-cnmh.inah.gob.mx/boletin/boletines/3EV16P74. pdf (consultado el 17 de septiembre de 2018).

Nolasco de Herrera, J. (1710). Discurso jurídico que propugna e informa el derecho que a la propiedad del Mayorasgo, que fundaron Juan Guerrero de Luna y Doña Beatriz Gomez Davila, su mujer, le asiste a Doña Maria Josepha Guerrero Davila, marquesa de el Villar de la Aguila, Poseedora de dicho Mayorasgo, en el pleito, que sigue con Don Juan de la Cueva y Don Joseph Moctezuma, sobre dicha propiedad; para que esta Real Audiencia se sirva de declarar pertenecerle; absolviendola de la 
demanda que por dichos sus Opositores se le deduxo, en que se exponen los fundamentos mas principales que patrocinan a su justicia, México, por los Herederos de la Viuda de Francisco Lupercio.

Ordaz, J. de (1710). Por Don Juan Diego Guerrero de la Cueva en el pleyto con Don Juan Antonio de Urrutia, del Orden de Alcantara, Marques del Villar del Aguila, como Marido y conjunta Persona de Doña María Guerrero, y con Don Joseph Moctezuma, sobre la possesion y propiedad del mayorasgo que con facultad Real fundaron Don Juan Guerrero de Luna y Doña Beatriz Gomez Davila su legitima mujer. Propongo algunos jurídicos meritos y fundamentos deducidos de la fundación, que demuestran la evidente justificación con que demanda para que esta Real Audiencia se sirva determinar a su favor, como pide. México: en la Imprenta de los Herederos de Juan Josef Guillena Carrascoso.

Ortega y Pérez Gallardo, R. (1908-1910). Historia genealógica de las familias más antiguas de México (3 vols.). México: Imprenta de A. Carranza y Compañía. (1902). Estudios genealógicos. México: Imprenta de Eduardo Dublán.

Pérez Rocha, E. (2018). La tierra y el hombre en la villa de Tacuba durante la época colonial. México: Secretaría de Cultura, Instituto Nacional de Antropología e Historia. https://books.google.es/books?id=SqWLDwAAQBAJ\&printsec=frontcover\&dq $=\mathrm{La}+$ tierra $+\mathrm{y}+\mathrm{el}+\mathrm{hombre}+\mathrm{en}+\mathrm{la}+\mathrm{Villa}+\mathrm{de}+$ Tacuba + duran te + la $+\%$ C3\%A 9poca + colonial \&hl=es\&sa $=X \& v e d=0$ ahUKEwjP84379IT jAhXBQEEAHehUC1kQ6AEIKDAA\#v=onepage \&q\&f=false (consultado el 14 de mayo de 2019).

Piqueras García, M. B. (2005). Certificación de Armas del apellido Oviedo. Emblemata, 11, 83-111.

Pompa y Pompa, A. (1988). 450 años de la imprenta tipográfica en México. México: Asociación Nacional de Libreros.

Postigo Castellanos, E. (1988). Honor y privilegio en la Corona de Castilla. El Consejo de las Órdenes y los caballeros de hábito en el siglo XVII. Valladolid: Junta de Castilla y León.

Ramírez Montes, G., y J. Iturrate (1979). Un ilustre ayalés en México. Juan Antonio de Urrutia y Arana (1670-1743). Vitoria: Caja de Ahorros Municipal.

Romero, Marta (2016). La Historia de la Encuadernación en México. Exposición de agosto a octubre de 2016. Museo Nacional de Historia, Castillo de Chapultepec. www.inah.gob.mx/es/boletines/5521-en-el-castillo-de-chapultepec-la-historia-de-la-encuadernacion-en-mexico (consultado el 27 de octubre de 2017).

Rosas García, J. (2015). El desarrollo de la élite novohispana: el mayorazgo de Gabriel López de Peralta como antecedente para la conformación del marquesado de Salvatierra (1608-1708). San Luis Potosí, El Colegio de San Luis. Url: https:// colsan.repositorioinstitucional.mx/jspui/bitstream/1013/298/3/El\%20de 
sarrollo\%20de\%20la\%20\%C3\%A9lite\%20novohispana\%20el\%20mayoraz go\%20de\%20Gabriel\%20L\%C3\%B3pez\%20de\%20Peralta\%20como\%20antece dente\%20para\%20la\%20 conformaci\%C3\%B3n\%20del\%20marquesado\% 20de\%20Salvatierra\%20\%281608-1708\%29.pdf (consultado el 14 de mayo de 2019) (tesis para obtener el grado de maestra en Historia, San Luis Potosí, 2015). (2015). El desarrollo de la élite novohispana: el mayorazgo de Gabriel López de Peralta como antecedente para la conformación del marquesado de Salvatierra (1608-1708). Tesis para obtener el grado de maestría en Historia, San Luis Potosí.

(2012). El germen de una élite novohispana: Gerónimo López "El Viejo" y Jerónimo López "El Mozo" (1521-1608). Tesis de licenciatura en Historia de México. Área Académica de Historia y Antropología. Pachuca: Universidad Autónoma del Estado de Hidalgo, Instituto de Ciencias Sociales y Humanidades.

Ruiz García, E. (2006). La carta ejecutoria de hidalguía: un espacio gráfico privilegiado. En la España Medieval. Estudios de genealogía, heráldica y nobiliaria, extra 1-29, 251-276. dialnet.unirioja.es/servlet/articulo?codigo $=2688784$ (consultado el 3 de septiembre de 2017).

Samaniego, F. de (1946). El marqués de la Villa del Villar del Águila. Querétaro: Edición Cimataria.

Vizcaíno, S. (1600). Una carta confirmatoria de hidalguía. En: Biblioteca Digital Mundial. Library of Congress, 74 ff., ils. https://www.wdl.org/es/item/517/ (consultado el 3 de septiembre de 2017).

Zárate Toscano, V. (2005). Los nobles ante la muerte en México. Actitudes, ceremonias y memoria (1750-1850). México: El Colegio de México/Instituto de Investigaciones Dr. José María Luis Mora.

\section{SOBRE LOS AUTORES}

Yohana Yessica Flores Hernández. Doctora en Ciencias de la Documentación por la Universidad Complutense de Madrid. Miembro del grupo de investigación sobre encuadernación y libro antiguo Bibliopegia y de la Asociación Española de Bibliografía. Profesora colaboradora honorífica de la Facultad de Ciencias de la Documentación.

José María de Francisco Olmos. Licenciado en Geografía e Historia, especialidad Historia Medieval; doctor en Historia por la Universidad Complutense de Madrid, donde es profesor titular de Ciencias Técnicas Historiográficas. 

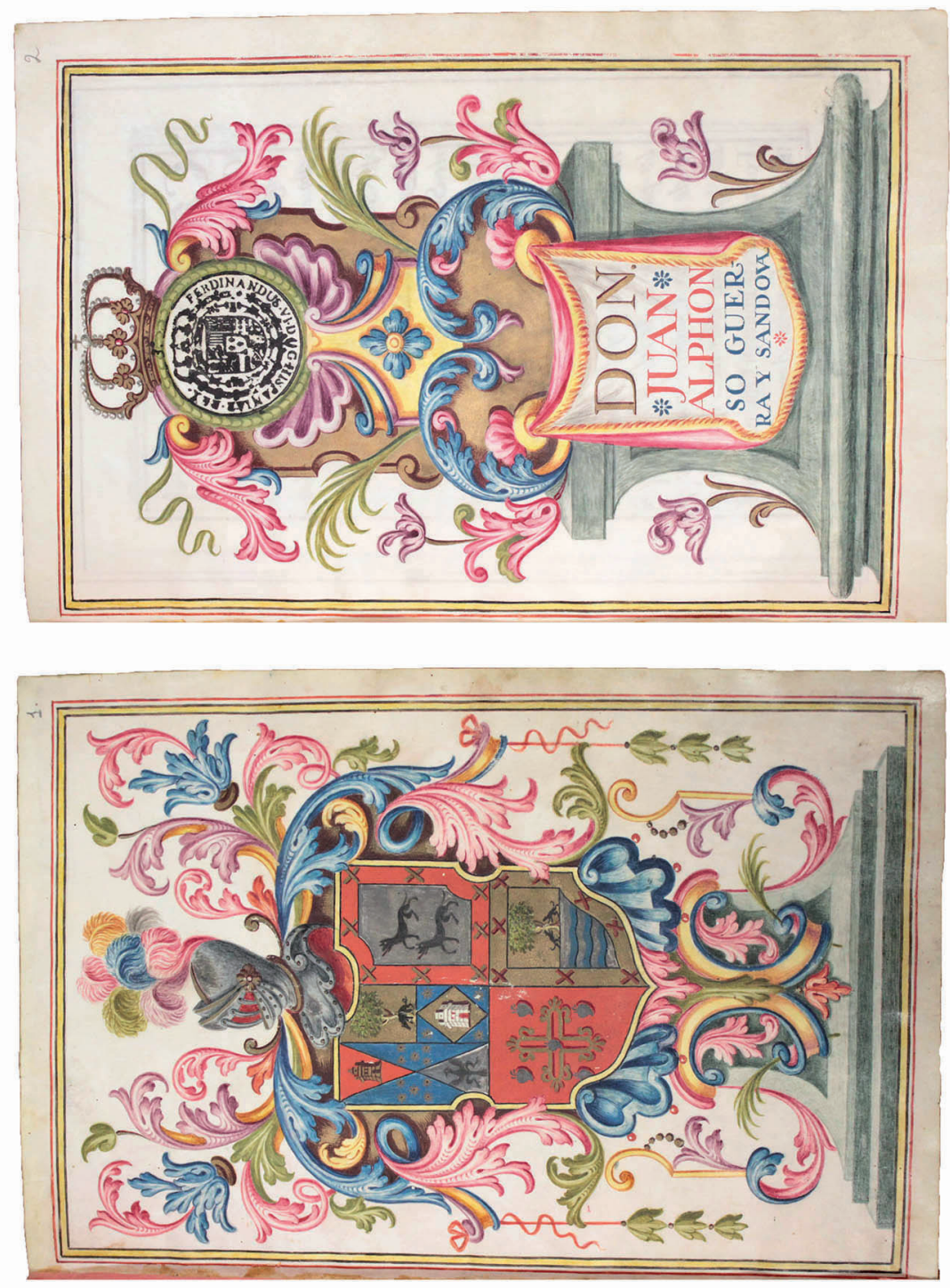

苞

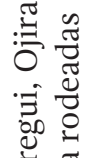

尝尝

ข)

ขै

ज क के

번 चै

I

.

: $\&$ \&

을 홍

เป็

응

궁 잉

घ 0

은 을

జี

ซิ

ข

음 它

过 $\frac{\pi}{\sigma}$

成

氙䒿

总艺

긱

承

元䨔

尝 

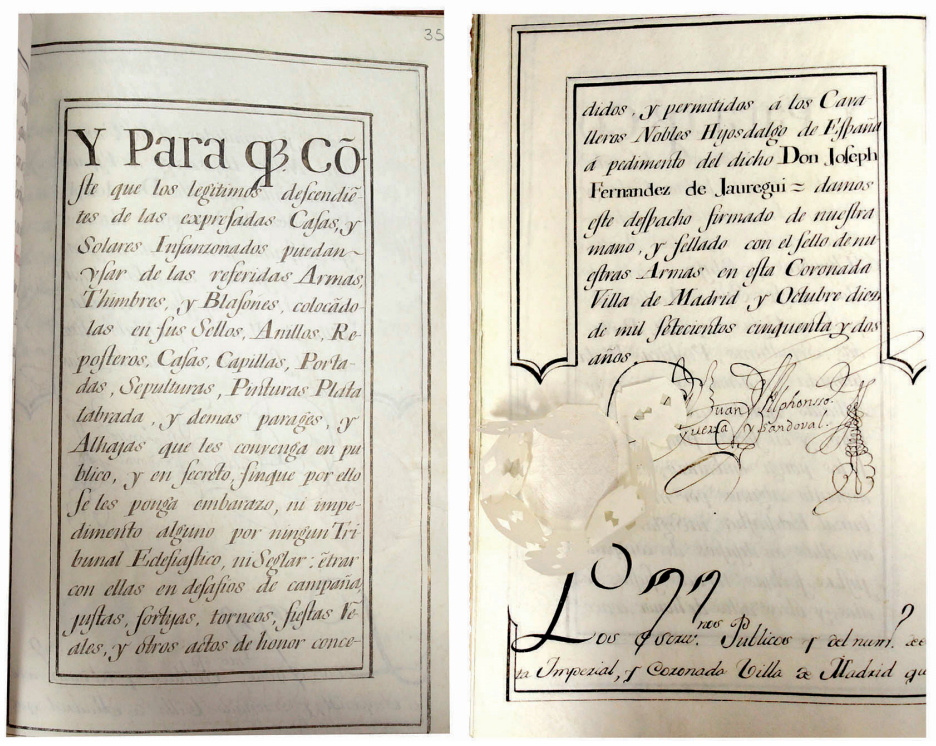

Figura 2. El folio de la izquierda indica que el peticionario podrá usar el escudo de armas que inicia la certificación de la forma que se expresa y no en otra y en el folio de la derecha aparecen la firma, la rúbrica y el sello del rey de armas Juan Alfonso Guerra Sandoval

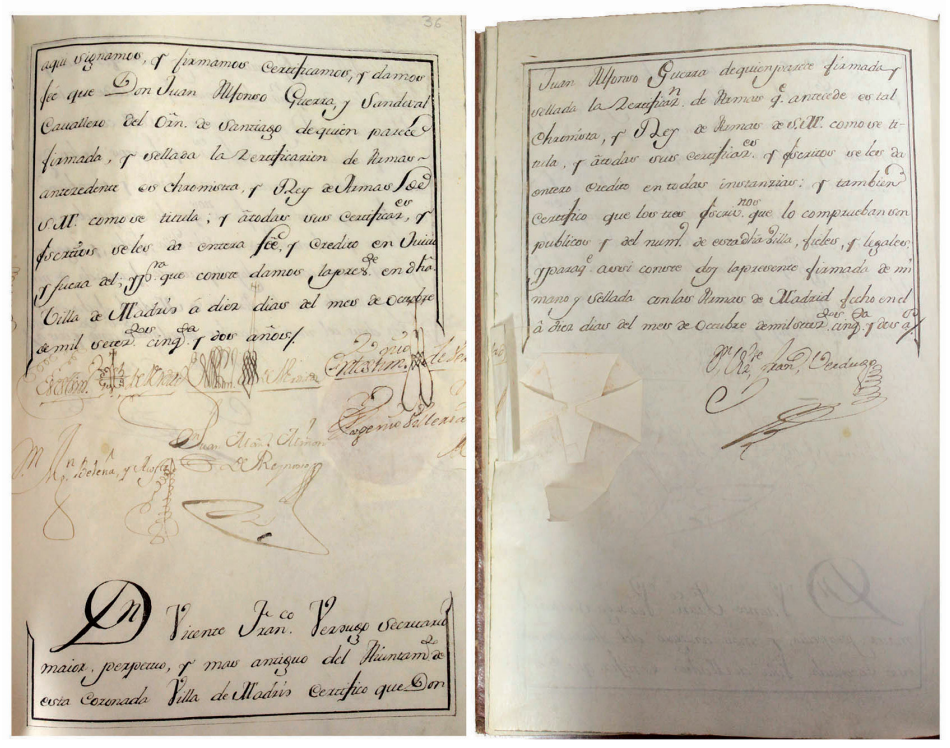

Figura 3. Los escribanos públicos de la Imperial y Coronada Villa de Madrid que certifican la validez del documento emitido por el rey de armas, y por fin la certificación de Vicente Francisco Verdugo sobre todo lo contenido en el documento 


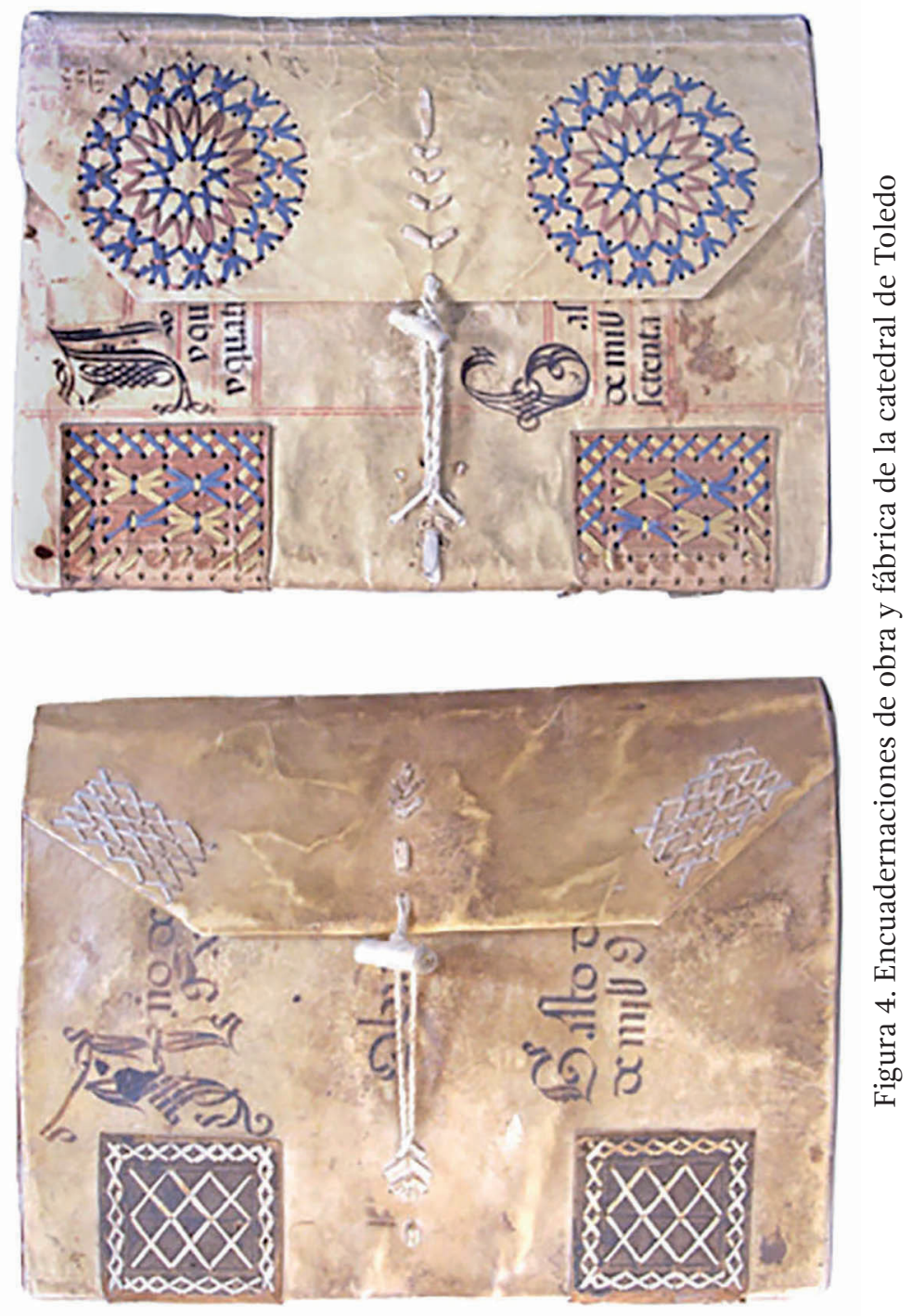



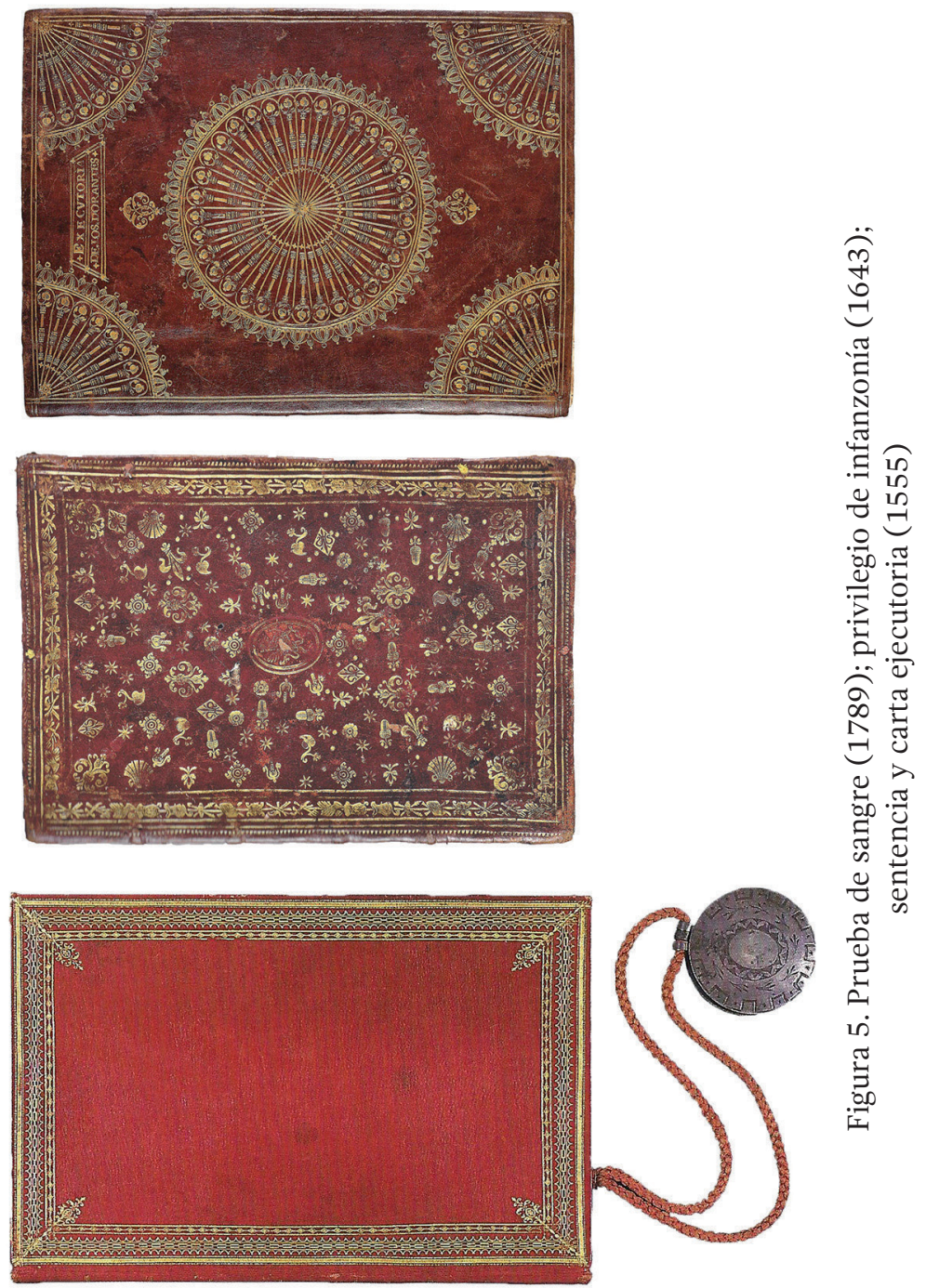

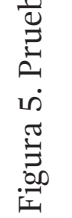




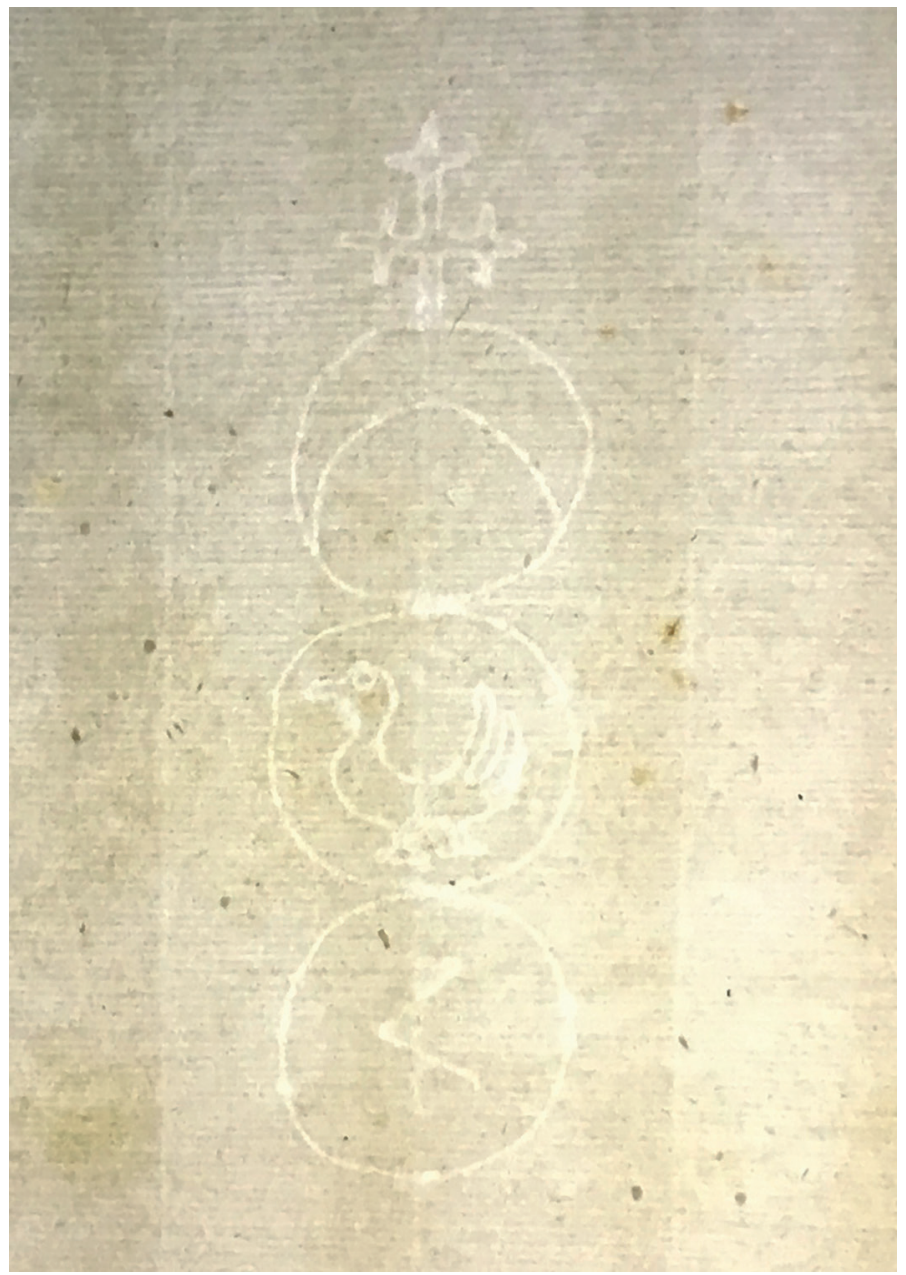

Figura 6. Detalle de papel verjurado y filigrana 


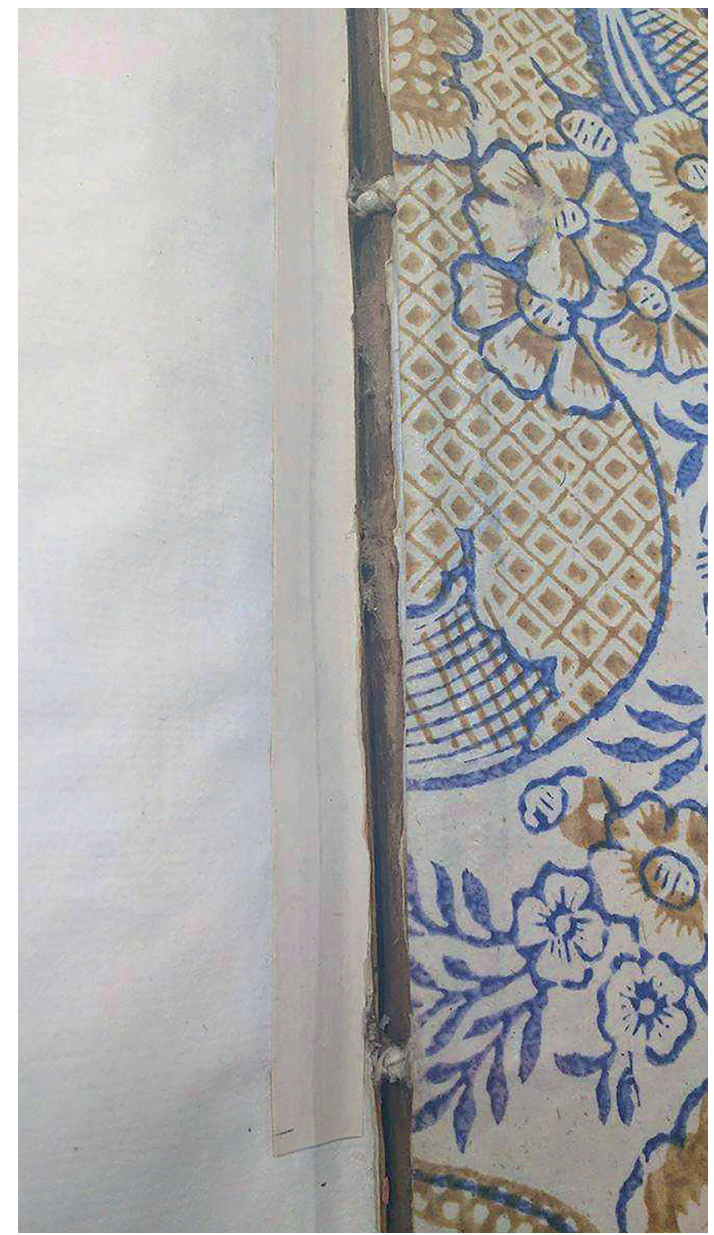

Figura 7. Detalle del encartonado 

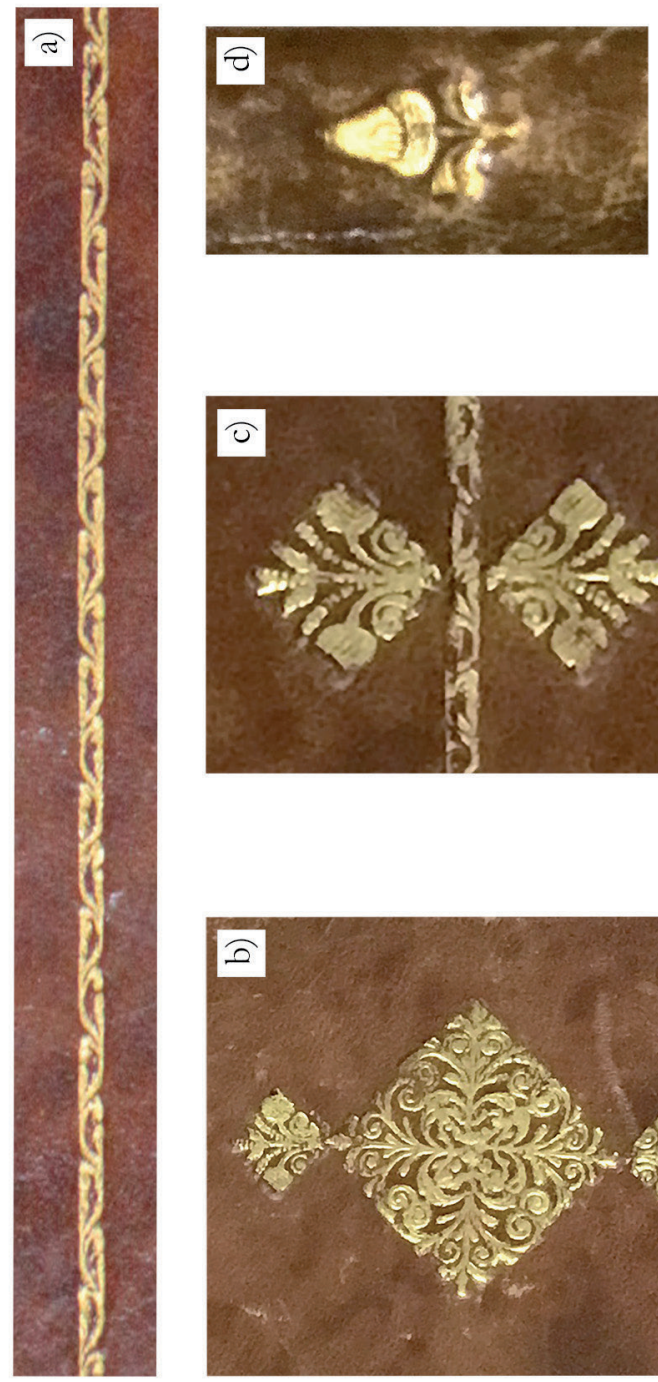

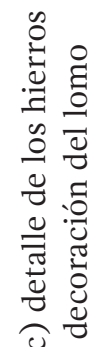

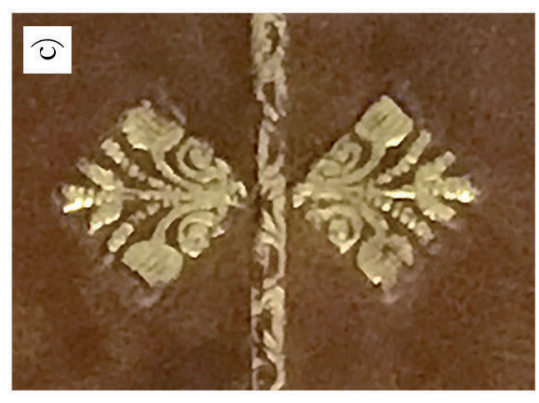

का

营

요유

:을

리

응을

즈

웅

웜

눰을

ลำ

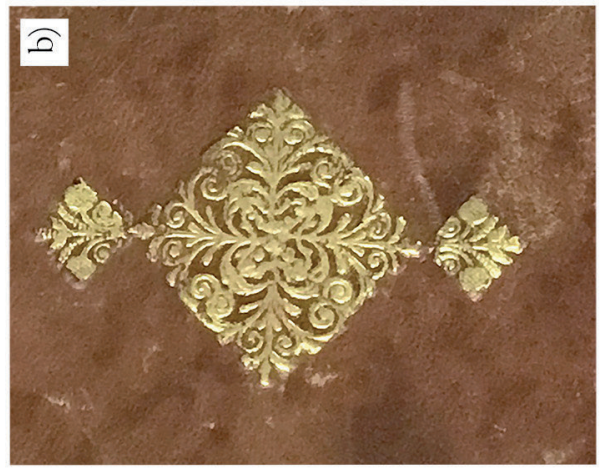

苞

기

주

요

号

过

สิ

$\infty$

ซ్

寻 


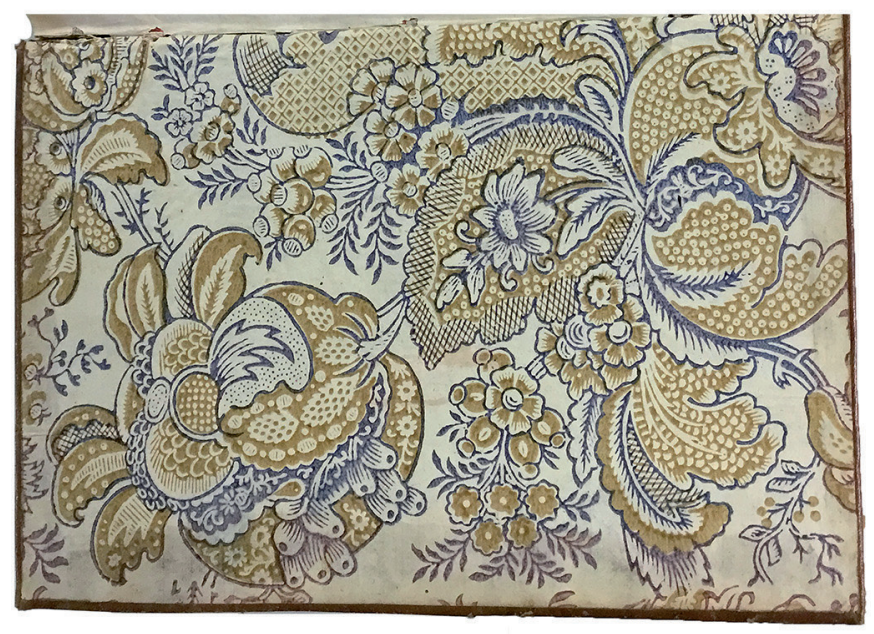

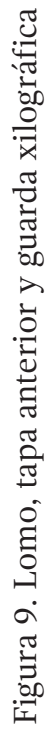
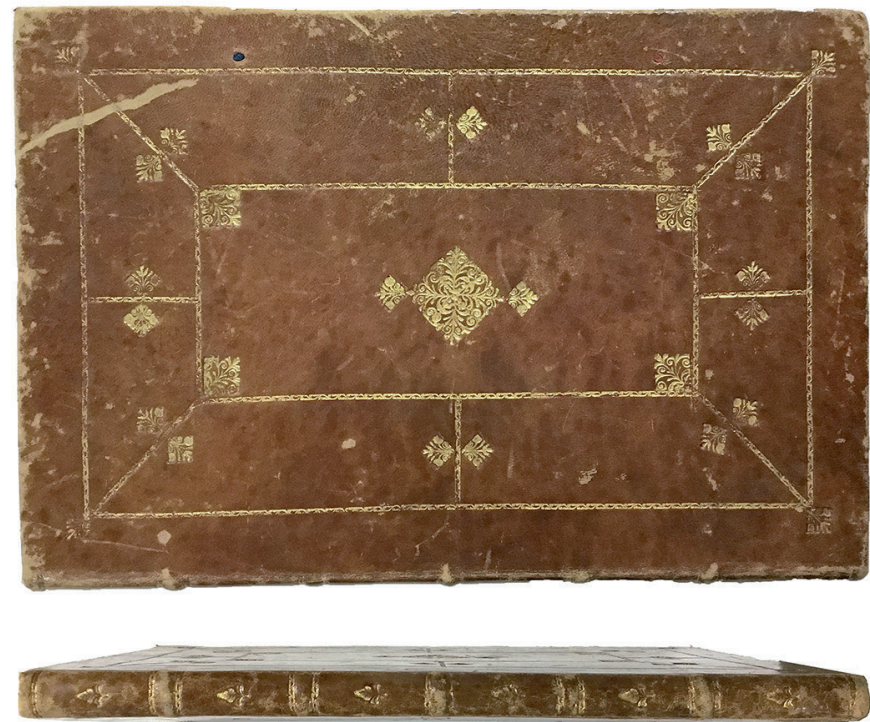